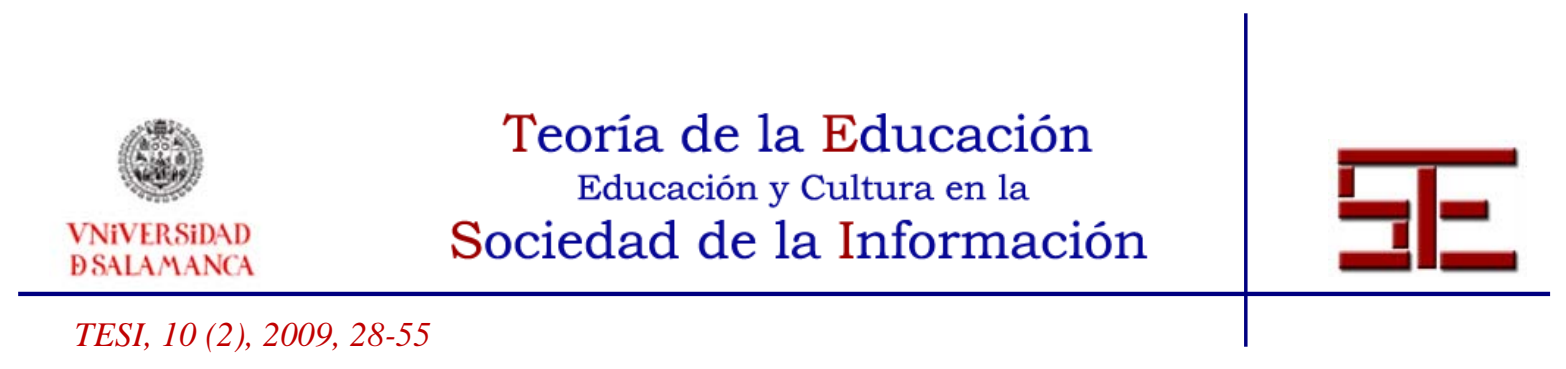

\title{
ALFABETIZACIÓN VIRTUAL Y GESTIÓN DEL CONOCIMIENTO
}

Resumen: La alfabetización digital se hace necesaria especialmente en las llamadas sociedades avanzadas. Hace referencia al grado de competencia de los ciudadanos frente a un objetivo concreto que es la capacidad para utilizar las herramientas digitales básicas. La habilidad es entendida como una cierta aptitud permanente que se consigue mediante la práctica en estas nuevas formas de tecnología. La Sociedad del Conocimiento y la información se caracterizan por el uso generalizado de estas nuevas tecnologías de la información y la comunicación (TIC) en cualquier entorno o actividad humanos que facilita la optimización de los recursos disponibles, ya sea a los individuos o a las organizaciones. La alfabetización digital se considera un proceso de aprendizaje significativo a través del cual se alcanzan los conocimientos tecnológicos necesarios para la utilización de lo que propiamente se podría denominar infotecnologías, con objeto de mejorar la calidad de los procesos y resultados en cualquier servicio o producto.

Palabras clave: alfabetización digital, gestión del conocimiento, cultura de las organizaciones, metodología.

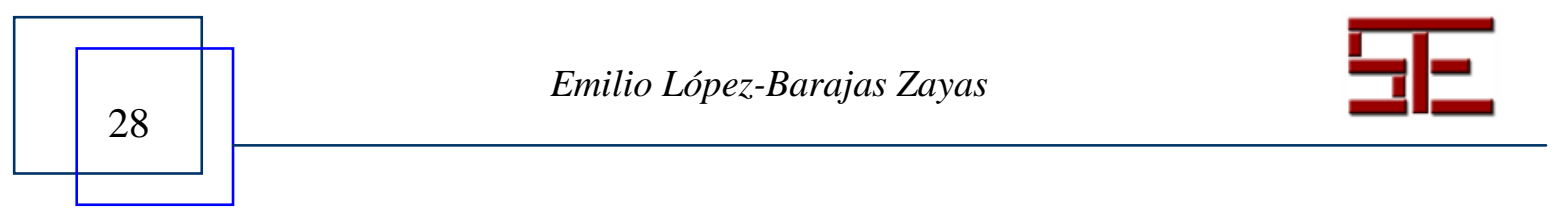




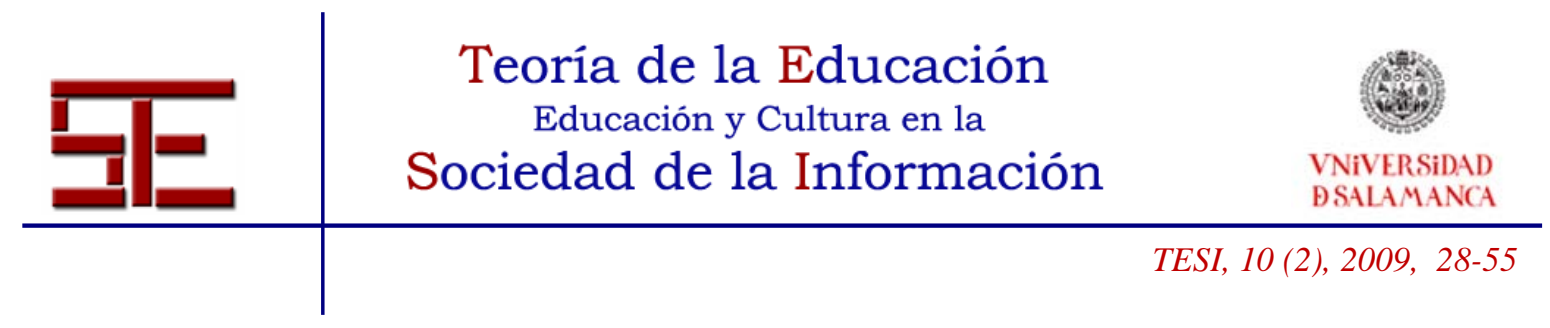

\section{VIRTUAL LITERACY AND KNOWLEDGE MANAGEMENT}

Abstract: Computer literacy has become a necessity, particularly in the so-called advanced societies. The term refers to the level of ability that citizens have to achieve a specific objective, which is to use basic computer tools. This ability is defined as a certain lasting skill acquired through practice in these new technological forms. The Knowledge as well as the Information Society are characterized by the general use of these new information and communication technologies (ICT), or refer to any human environment or activity that facilitates the streamlining of available resources, whether for individuals or organizations. Computer literacy is considered a significant learning process through which the necessary technological knowledge is acquired to exploit what might be more precisely referred to as info-technologies, for purposes of improving the quality of processes and results for any service or product.

Keywords: computer literacy, knowledge management, organizational culture, methodology.

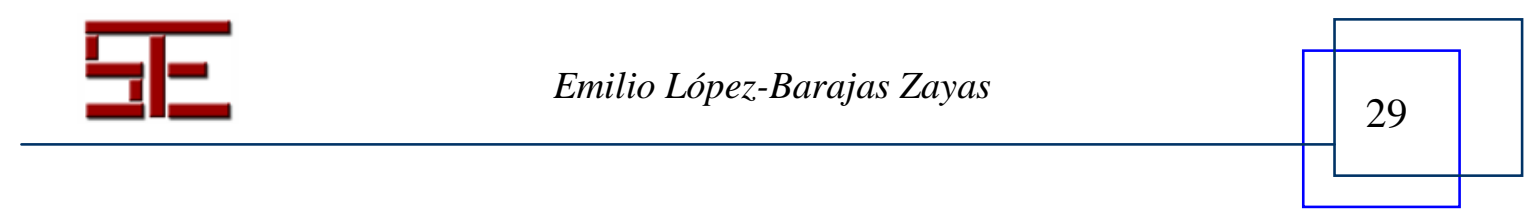




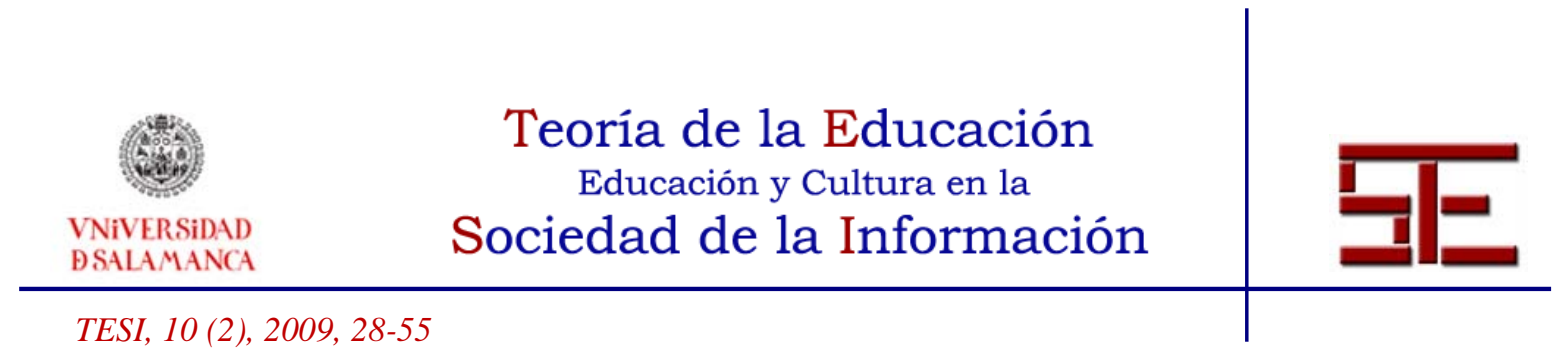

\section{ALFABETIZACIÓN VIRTUAL Y GESTIÓN DEL CONOCIMIENTO}

Emilio López-Barajas Zayas

elopez-barajas@edu.uned.es

Universidad Nacional de Educación a Distancia.

\section{1.- INTRODUCCIÓN}

Los educadores, y en general la ciudadanía, han de saber que la alfabetización digital es un derecho del ciudadano en la sociedad moderna, y que hoy ésta adquiere nuevos matices y exigencias como son: el conocimiento como usuarios de las Nuevas Tecnologías de la Comunicación y la Información, como medio para incorporarse a la vida social y laboral. La ausencia de dichos conceptos y ciertas habilidades básicas (basic skills) propicia, particularmente en las sociedades más avanzadas, el problema social grave de la exclusión laboral. Las conclusiones del Internacional Adult Literacy in the Information Age, publicadas en junio de 2000 señaló ya en esta fecha que de los veinte países de la muestra, al menos el $15 \%$ de los adultos de la misma se situaba en niveles bajos de alfabetización lo que presentaban serias dificultades para responder a las demandas de formación necesarias del mercado dados los perfiles de la Sociedad del Conocimiento (López-Barajas Zayas, 2006, 20). La competencia que ahora es necesaria no es solo acerca de la habilidad para leer textos en prosa, la comprensión de documentos, y la comprensión de textos cuantitativos, sino también, del conocimiento digital y la aplicación de la informática básica de usuario.

La finalidad principal de este trabajo es advertir de la importancia que la alfabetización virtual y la gestión del conocimiento tendrán en el futuro en las formas de producción y trabajo de las organizaciones y la calidad total. La alfabetización digital, si hubiese el coraje político necesario desde el llamado primer mundo, dotaría de las infotecnologias necesarias y la formación permanente correspondiente a las zonas culturalmente más deprimidas, lo que podría ser uno de los factores más dinámicos de prosperidad y progreso en las zonas económicamente menos desarrolladas, al dotarles con las herramientas propias de la infotecología. La e-educación reduce los costes y mejora la competencia del ciudadano para intervenir en las sociedades sometidas a esta tercera revolución tecnológica. La Cumbre Mundial sobre la Sociedad de la Información (CMSI-WSIS), ya manifestó esta necesidad en el año 2003.

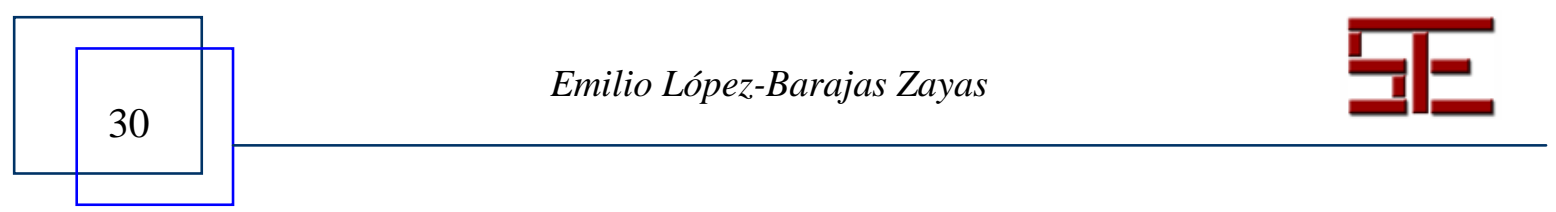




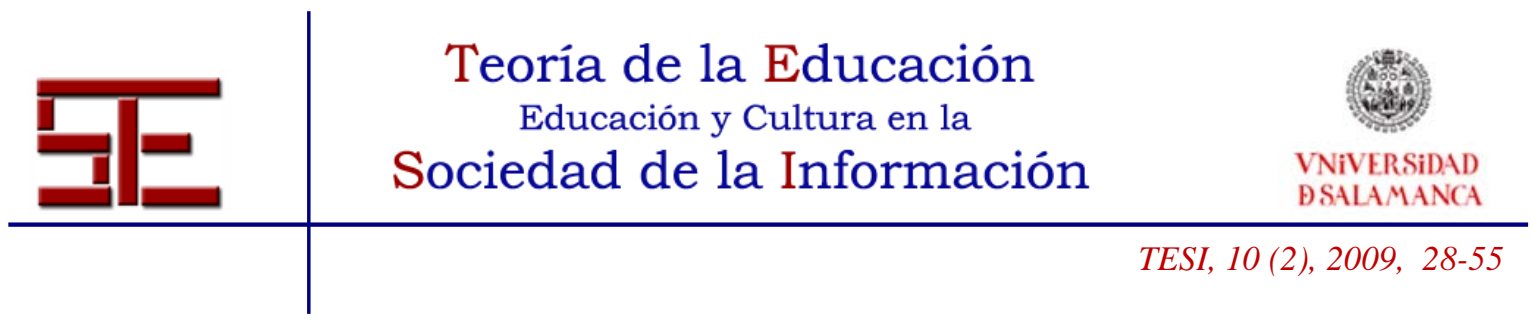

Las personas, las empresas y las organizaciones, además, necesitan adaptarse a los cambios del medio en el que desarrollan sus actividades. La formación ha de preparar para saber "cómo hacer" en los nuevos escenarios. Cuando el know - how de una empresa, su gama de productos (o servicios), sus relaciones laborales, están en armonía con el entorno, la tarea fundamental de la dirección se convierte en la asignación de recursos.

La Gestión del conocimiento, dado el valor añadido que ello significa, requiere nuevos formatos, en los que el texto es la forma de transmisión, es decir, el soporte son los documentos. Un documento ha de entenderse en sentido amplio ya que puede ser: una hoja escrita, un artículo, un libro, un diagrama, una fotografía, una cinta de video, un DVD, una base de datos, una página web, etc. La formación ha de establecer programas para desarrollar la capacidad de todos en la redacción de textos.

Reflexionaremos, además, acerca del concepto más general de Mundos Virtuales (MV) que son, como su nombre indica, entornos artificiales, semejantes a la vida real, en los que el hombre interacciona con otros a través del ordenador y usando un avatar (realidad virtual). Un Mundo Virtual permite: a) Que los alumnos o usuarios del entorno puedan a su vez rediseñar el mismo, además de la utilización de los que están disponibles; b) las realidades virtuales o avatares pueden ser editados y personalizados según los intereses y objetivos didácticos; c) la comunicación se realiza en la práctica a través de Chat de texto o de VoIP (Voice over Internet Protocol); c) permite, además, el ecommerce integrado; d) cualquier suceso de la comunidad, o acontecimiento relevante de interés general, se pueden difundir públicamente.

\section{2.-ALFABETIZACIÓN DIGITAL}

¿Qué es la alfabetización digital? Existe un debate en el entorno académico y profesional acerca de su estatuto epistemológico, es decir, acerca de la naturaleza, estructura y finalidad de la misma. Y, además, a los educadores, y formadores en general, preocupa la llamada brecha digital que es una realidad observable en numerosos países y contextos, y que se evalúa socialmente como un nuevo indicador de las desigualdades existentes en esta era globalizada. La caracterización de la alfabetización funcional recoge en el "campo semántico" propio, es decir, relacionado con esta expresión de alfabetización digital diversas expresiones o términos como los siguientes: alfabetización informacional, computacional, tecnológica, electrónica, etc.

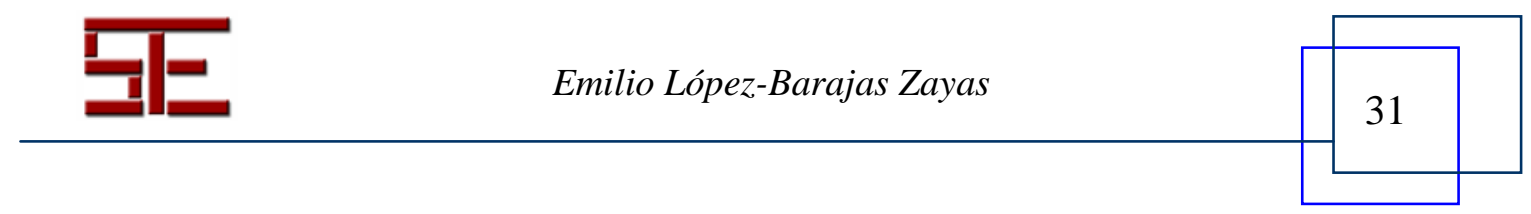




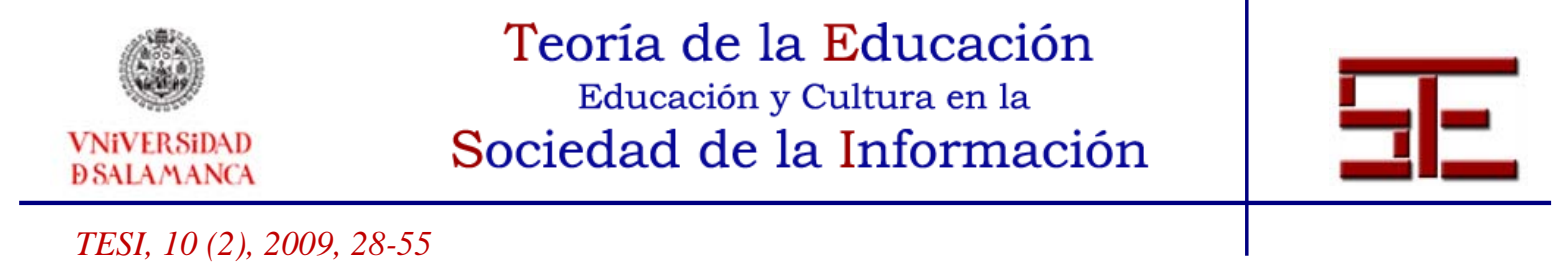

Más allá de definiciones nominales, la alfabetización se refiere a ciertas habilidades que son necesarias para que los ciudadanos se incorporen a las formas de producción y de trabajo. El peligro, según hemos indicado, es la brecha digital en la realidad de la Globalización, que comienza con la exclusión laboral, y alcanza también una brecha social, donde se ponen de relieve las diferencias injustas de los distintos grupos humanos o áreas culturales, diferencias que tienen primariamente una razón socioeconómica de distribución desigual. La dificultad para acceder a la alfabetización funcional crece en aquellos ciudadanos de áreas actualmente no suficientemente desarrolladas o que históricamente están en vías de desarrollo para alcanzar las propuestas del movimiento de la Educación para Todos, y que también se manifiestan obviamente en la posibilidad del acceso a la información y la comunicación, lo que llega a determinar que la significación del término alfabetización sea muy diferente de unos países a otros. Algunos países en el mundo aun no han conseguido la plena incorporación siquiera de sus niños y niñas a los estudios primarios.

Sin embargo, la alfabetización digital se hace necesaria especialmente en las llamadas sociedades avanzadas, según hemos indicado, porque hace referencia al grado de competencia de los ciudadanos frente a un objetivo concreto que es la capacidad para utilizar las herramientas digitales básicas. La habilidad es entendida como una cierta aptitud permanente que se consigue mediante la práctica en estas nuevas formas de tecnología. La Sociedad del Conocimiento y la información se caracterizan por el uso generalizado de estas nuevas tecnologías de la información y la comunicación (TIC) en cualquier entorno o actividad humana que facilita la optimización de los recursos disponibles, ya sea a los individuos o a las organizaciones. La inclusión digital es un reto común a las personas y las organizaciones. Inclusión que pasa por un proceso de formación de los formadores en estas nuevas formas de aprendizaje (López-Barajas Zayas, 2007, 66-67). La alfabetización digital se considera un proceso de aprendizaje significativo a través del cual se alcanzan los conocimientos tecnológicos necesarios para la utilización de lo que propiamente se podría denominar infotecnologías, con objeto de mejorar la calidad de los procesos y resultados en cualquier servicio o producto. La competencia en las infotecnologías es el supuesto necesario que permite la Gestión del conocimiento ya sea a nivel individual, o de la organización.

El ciudadano necesita, en las sociedades avanzadas tecnológicamente, la posibilidad de realización de un aprendizaje continuo, a través de los programas de educación permanente necesarios con objeto de no quedar excluido laboral y socialmente. La incorporación ha de ser también crítica ya que esta modalidad de aprendizaje tiene

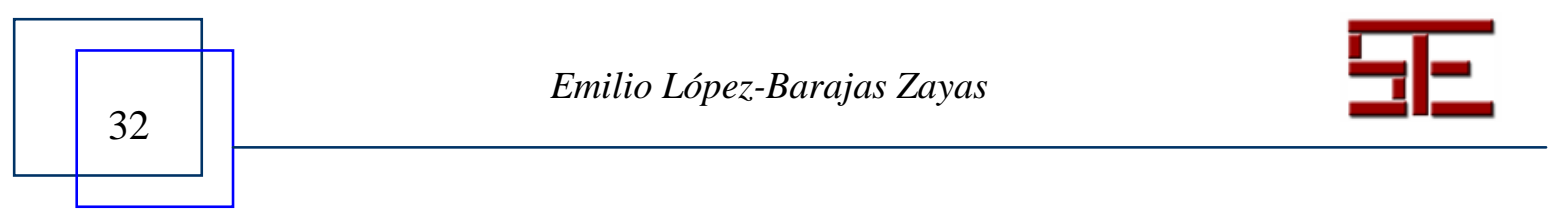




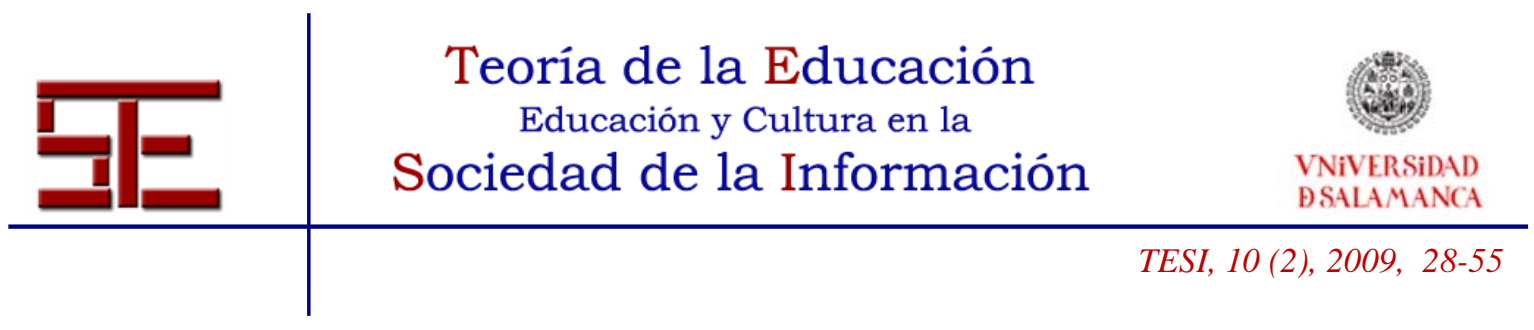

debilidades propias derivadas de su diseño propio, originado en una cultura técnica y una perspectiva epistemológica propia de la antropología exclusivamente cultural; pero también tiene sus potencialidades, aspectos positivos, al permitirle al usuario una formación ciudadana que le motive a la participación, colaboración y servicio social, a través de las numerosas redes. Los ciudadanos, además, en el mundo laboral necesitan incorporar las infotecnologías para ser competitivos individual, social, y económicamente. La educación de adultos, como señala García Carrasco, se considera parte de la educación permanente, a partir de los años cincuenta del siglo pasado, a través de las Conferencias organizadas por la UNESCO (Cfr. García Carrasco, 1997, 281-284).

La alfabetización digital por consiguiente afecta a la Gestión del conocimiento en todos los sectores de la vida social, cultural, artística, y laboral. Las formas de vida son impulsadas, por consiguiente, por un dinamismo creciente, que se deriva de la aparición de nuevas formas de infotecnología. La alfabetización digital es algo más que la habilidad humana del ciudadano para la utilización del ordenador personal y la navegación por la red, ya que el reto se abre hacia la competencia que alcanza la información de calidad necesaria en un universo en cambio. Objetivo específico que requiere criterios, insistimos una vez más, de crítica técnica y ética. La perspectiva crítica se deriva de la utilización del método crítico moderno, y además al entender la racionalidad como fuente desde la que fluye lo mejor del espíritu humano.

La alfabetización digital, desde su proceso funcional, particularmente para la Gestión del conocimiento, requiere de medios técnicos (hardware y software) adecuados que soporten la "arquitectura digital” y los programas de formación correspondientes para el desarrollo de las competencias en cada caso. Los medios técnicos se han de corresponder con el soporte material que sea necesario. Las "herramientas" han de ser aquellas que sean suficientes para estimular y motivar los procesos de aprendizaje que permitan alcanzar las habilidades necesarias, las competencias que sean pertinentes para desarrollar la metodología de la Gestión del Conocimiento.

La metodología activa de la alfabetización digital cobra un relieve de extraordinaria importancia al considerar que ya que son más de 1.000 millones los internautas que ya están conectados; ciertamente si Europa y Estados Unidos ya suman unos 550 millones, en el continente africano no hay más de un 5\%. Diferencias que acentúan la brecha digital si se consideran los grupos de incidencia crítica: mujeres, zonas rurales, estatus social, inmigrantes, etc. Además, Nielsen/NetRatings ha presentado una análisis de

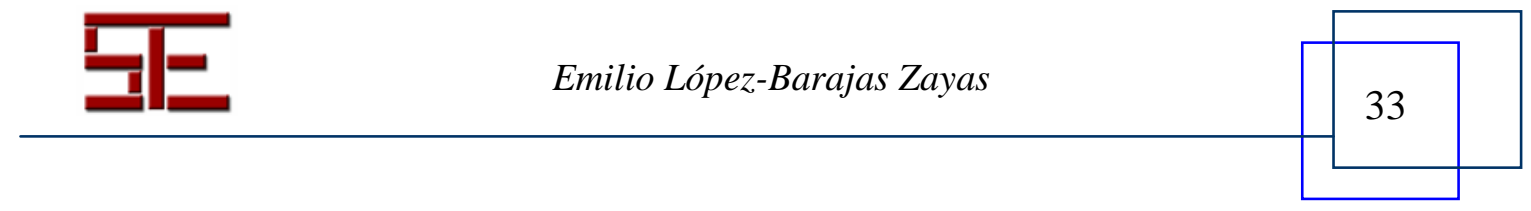




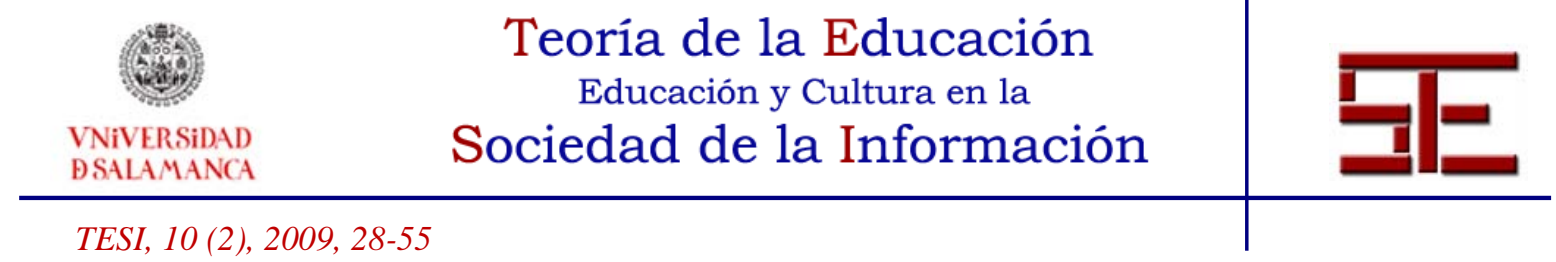

audiencia con los websites más visitados en el mundo: AOL/Time Warner, con 78 millones de visitantes, Microsoft con 74 millones de usuarios, Yahoo con 66 millones, Google con 29 millones de visitantes y eBay con 28 millones.

La Gestión del Conocimiento a nivel personal y de las organizaciones es necesaria. No es tanto una tarea propia de la tecnología cuanto de la cultura personal y de la organización. La formación es la fuerza que dinamiza la Gestión del Conocimiento, donde el aprendizaje significativo se configura en un complejo o amalgama de conocimientos, experiencias, actitudes, aptitudes e intereses y modos de resolución de problemas. Queremos significar que sí las herramientas son necesarias aun más importante es saber cómo utilizarlas. En la Gestión del Conocimiento confluyen principios de la formación, de la sociología y la psicología, además de los propios derivados de la informática y las ciencias de la comunicación. Quizá sea por ello que las expectativas de crecimiento del mercado de servicios y software sean crecientes. Aun siendo central el proceso del aprendizaje la forma de la actividad formativa es decisiva, aun considerando su carácter transitivo (al servicio del sujeto que aprende). Hemos dicho que es central el aprendizaje, porque éste tiene un carácter inmanente. Queremos decir que el formador puede hacer mucho en el proceso de formación pero si el alumno no se aplica y esfuerza el resultado será negativo. El formador ha de "hacer hacer". El contenido del aprendizaje puede ser más o menos atractivo pero sin el esfuerzo del discente siempre será una tarea a mitad de camino. Se puede utilizar alguna técnica lúdica incluso pero el aprendizaje es una tarea ardua y costosa que exige constancia y esfuerzo. La organización, por su parte, necesita de la competencia de todos; y, al mismo tiempo, de la experiencia de todos. Formación y colaboración son dos indicadores de la capacidad futura de la empresa y en general de cualquier organización (López-Barajas Zayas, 2006).

\section{3.- LA ALFABETIZACIÓN Y LA CULTURA DE LAS ORGANIZACIONES}

La alfabetización digital tiene en las organizaciones una valiosa misión: el desarrollo de las potencialidades, y la asistencia a las carencias de los Recursos Humanos, ya que el Capital Humano es el conjunto de las personas, en un contexto de participación, de trabajo equipo, ya que en el "entorno interno" actual de las organizaciones, no hay persona que tenga todas las respuestas, las habilidades y la sabiduría necesarias, para guiar a la organización hacia un éxito sostenido, a no ser que utilice y maximice las respuestas y las habilidades del conjunto de la organización. En definitiva, para que la

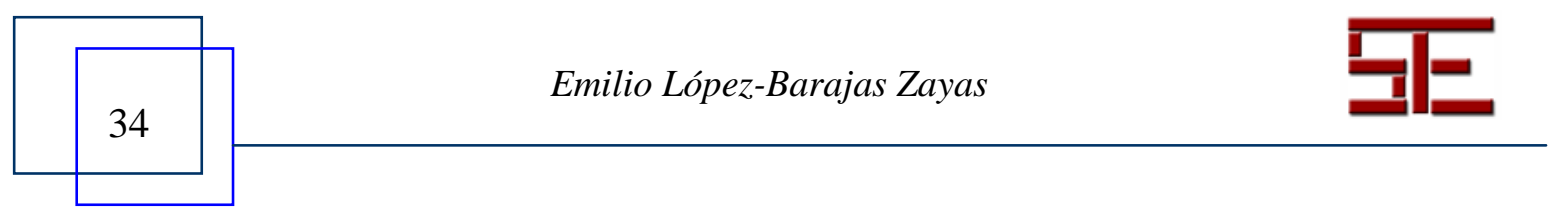




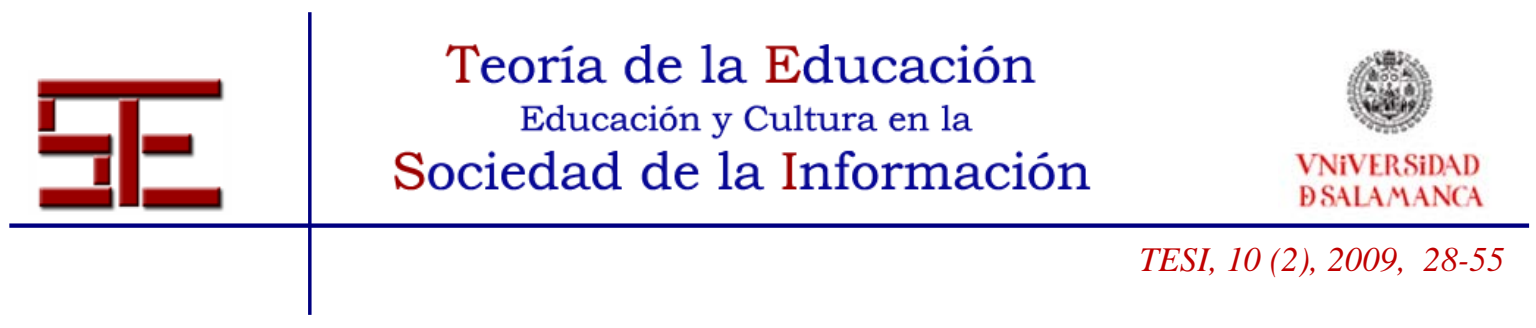

empresa triunfe, debe encontrar la forma de maximizar las aportaciones de sus miembros (Gil, 2001).

Los recursos humanos y financieros se asignan a las partes mejor preparadas para sacar provecho de un entorno convergente y en armonía. Por el contrario cuando las políticas son divergentes y poco armoniosas, éstas se convierte en la práctica, en políticas o directrices generales de supervivencia Y esto ocurre así, porque en tiempos de expansión, la euforia no percibe con claridad los cambios que se avecinan (Herreros, 2000).

Algunos docentes muestran una actitud de resistencia al cambio. Otros no comprenden la necesidad del mismo, o la forma particular en que se ha definido y se pretende aplicarlo, y algunos muestran actitudes de enfrentamiento al mismo. Un hecho parece claro, desde la óptica psicológica, el cambio produce una cierta ansiedad, ya que unas veces, son conceptos, ideas, e instrumentos nuevos que no se dominan, y que por tanto procede una cierta inseguridad, la ansiedad es ante la impotencia del aprendizaje que se nos propone. El horizonte de los objetivos generales, otras veces, no parece alcanzable. La ansiedad de supervivencia trata de superar la del aprendizaje, o reducir la distancia consiguiendo metas menores. Un hecho parece claro cuando el usuario de un programa de formación percibe que los objetivos no son alcanzables, o están faltos de significación para él, ni siquiera intentará conseguirlos (López-Barajas Zayas, 2006). Y esto sea así, porque la facilidad para la respuesta a la innovación tiene que ver con la cultura actual de la organización. La cultura del futuro es corporativa dado que el reto que se abre en el horizonte es de naturaleza interdisciplinar ¿Qué es la cultura de la organización? La cultura de las organizaciones es el conjunto de conocimientos, competencias, aptitudes y actitudes del conjunto de las personas que trabajan en ella. La cultura, por otra parte, aun siendo impulsada por la formación, evoluciona muy lentamente, ya que hay una cierta inercia en lo individual y también en los grupos sociales como son las empresas y organizaciones, ante el cambio se responde que es mejor "seguir como siempre". De lo que no cabe duda es que la solución a muchos de los problemas que se plantean hoy a las empresas y organizaciones pasa por la el aprendizaje permanente. A través de éste, no solo se evitará la marcha de personas valiosas desde la organización, sino que se podrá atraer recursos humanos competentes a la nuestra, y, en general, se podrá motivar a todos convenientemente, lo que tendrá como consecuencia su fidelidad a la compañía o la institución, y la mejora de los procesos normativos. Pero estos objetivos no serán viables si la organización no evoluciona y se adapta a las nuevas exigencias y cambios sociales y del mercado. En

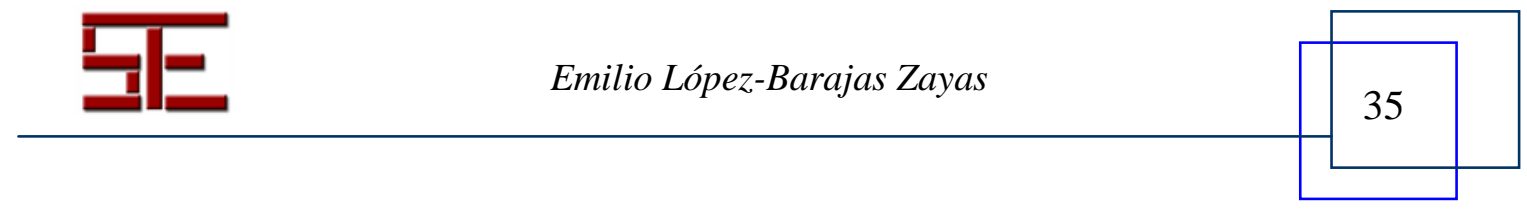




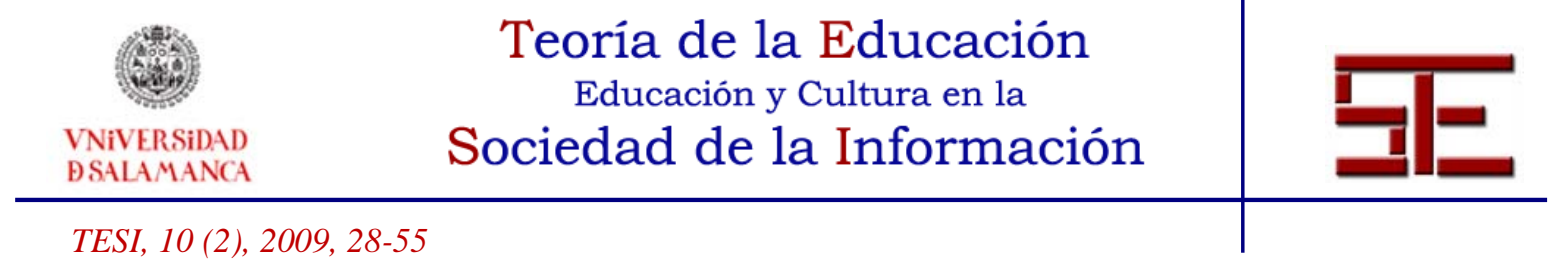

este sentido deben ser observadas de forma permanente algunas variables independientes: los sucesivos avances tecnológicos, el proceso de la globalización e internacionalización de la competencia y la dispersión de los equipos de trabajo (Flores, 2000). La Gestión del caudal del Conocimiento de la organización realizado de forma adecuada se convierte en un factor relevante de eficacia y eficiencia.

Sin entrar en juicios de valor, asistimos a un cambio de cultura política y a un escenario del predominio de la iniciativa social privada, que afecta a las tres cuartas partes de la población mundial, que da una nueva dimensión al fenómeno y pone el énfasis, precisamente, en esta iniciativa, y en la liberalización económica, como fuerzas de expansión. Otro factor de gran importancia es el cambio tecnológico acelerado ya señalado, que afecta tanto a la innovación de productos como a la formación de nuevas estructuras industriales en competencia, y tiene su manifestación en la potencialidad de la creación de riqueza (Mateos, 2001). La formación no ha de desconocer estos movimientos generales para el desarrollo de las competencias de los trabajadores actuales o futuros. De hecho, los agentes sociales, ejerciendo su responsabilidad fomentan los Planes, proyectos y programas de formación para sus afiliados.

\section{4.- LAS PLATAFORMAS DIGITALES Y LA GESTIÓN DEL CONOCIMIENTO COMO PROYECTO INTELIGENTE}

En el campo de relación semántica de la expresión Gestión del Conocimiento encontramos entre otras las siguientes: capital intelectual, gestión de la información, sistema de información, intranet corporativa, etc. Se podría resumir el sentido implícito en ellas diciendo que la Gestión del Conocimiento es un proyecto inteligente de trabajo corporativo. Y esto es así, porque un proyecto humano ha de tener un fundamento de inteligencia creativa. Proyectar es mirar hacia un horizonte ciertamente lejano. Es decir, el proyecto supone anticipación, nos aleja del horizonte presente, previsible, lo que supone una cierta anticipación que hacemos los seres humanos del futuro que llegará (Marina, 1993).

La organización actualmente se convierte en una inteligencia innovadora. La inteligencia transformadora supone un proceso de aprendizaje que examina y evoluciona desde los supuestos actuales bajo los que opera la organización y desarrolla nuevas prácticas organizativas basadas en supuestos nuevos. No podemos ser formadores unidireccionales, hemos de favorecer el pensamiento divergente, que proyecta diversas alternativas para el futuro.

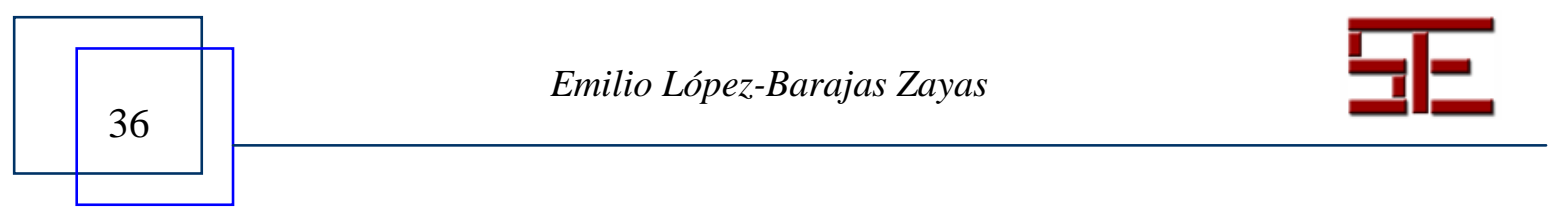




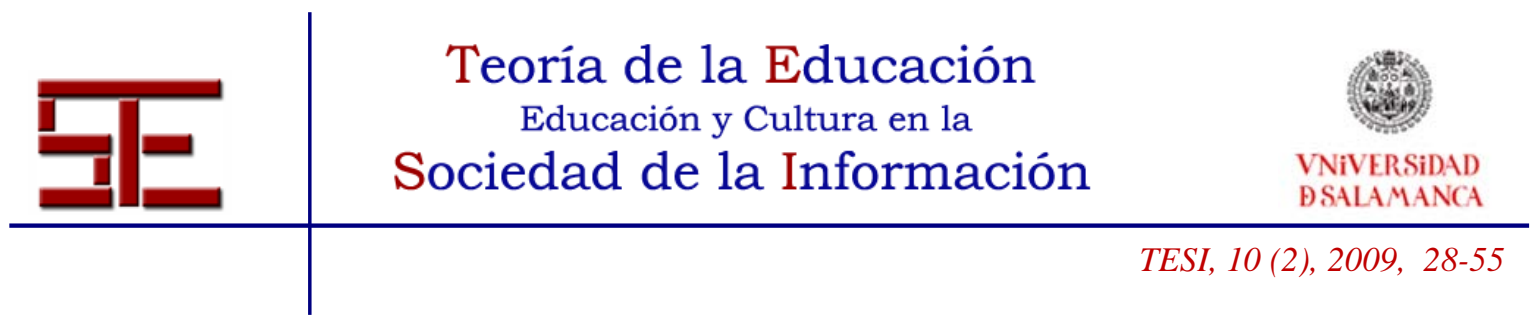

La Gestión del Conocimiento, y la metodología de documentación del mismo, trata de hacer participar a todos en el proyecto. Habrá que decir que las decisiones de los directivos de la organización no suponen una siempre una respuesta absoluta. El análisis de los problemas es complejo. Cualquier decisión se verá afectada por varios factores: el grado de estructuración del problema, la definición adecuada del mismo, el riesgo inherente a la decisión, el grado de incertidumbre o certeza, y el conflicto u oposición que generan. La suma del conocimiento y la experiencia de todos puede optimizar la decisión, dicho en términos técnicos: maximiza la varianza sistemática primaria, es decir, encontrar los valores óptimos en la toma de decisión en la mayoría de los problemas y escenario dinámicos. ¿Cómo recoger y gestionar el conocimiento de la organización? (López-Barajas Zayas, 2006, 250).

Los SRM (Services Relationship Management) son herramientas virtuales para afrontar necesidades específicas para la Automatización de Servicios Profesionales que racionalizan los procesos internos de la empresa y permiten la comunicación a través de Internet, con clientes, proveedores, compañeros, y colaboradores o consultores independientes (Herreros, 2000). La formación se ocupara de capacitar a los miembros de la organización en estos nuevos lenguajes. El concepto CMR (Costumer Relationship Management) frente a la visión tradicional de la empresa centrada en el producto o servicio, manifiesta una perspectiva formal orientada a todos los procesos para satisfacer al cliente o usuario (necesario en un mercado competitivo o exigente); se podría decir que el cliente toma la última decisión. No es solo un concepto tecnológico para automatizar las labores de la fuerza de venta (departamentos comerciales), sino cambio de mentalidad para orientar la compañía hacia el cliente (Flores, 2000). El centro de la Gestión del Conocimiento se orienta al conocimiento de las demandas del cliente o usuario (López-Barajas Zayas, 2006).

El educador debe tener presente que la estrategia es superior a la técnica y ésta a la táctica, ya que la primera elige "el campo de batalla”, prevé el tiempo y los espacios futuros para la acción. La inteligencia positiva se caracteriza, como su nombre indica, por el sentido positivo, y de forma particular, por la proyección en el futuro de planes y proyectos de interés. La esperanza humana, lo reiteramos, necesita de un proyecto futuro. Cuantas más alternativas de proyectos se tengan, la vida humana se hace más atractiva e interesante. La formación ha de desarrollar en los usuarios actitudes esperanzadas, ha de estimular proyectos diversos en el horizonte, no solo a nivel individual sino de la propia empresa u organización. La "lucha" ha de ser pacífica y solidaria. El propósito de la estrategia de Gestión del Conocimiento, en una fase

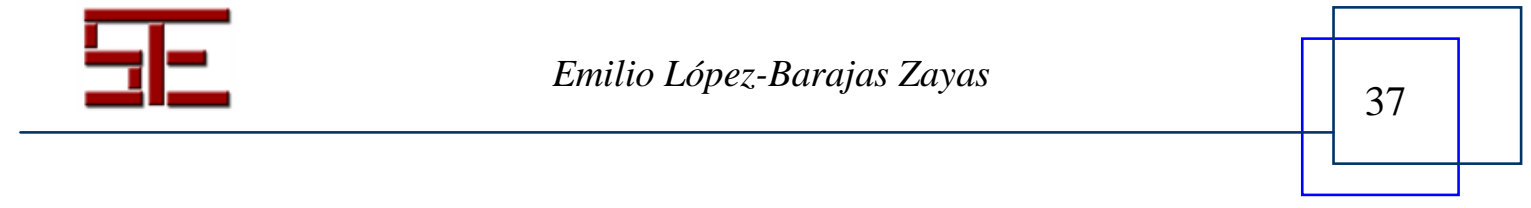




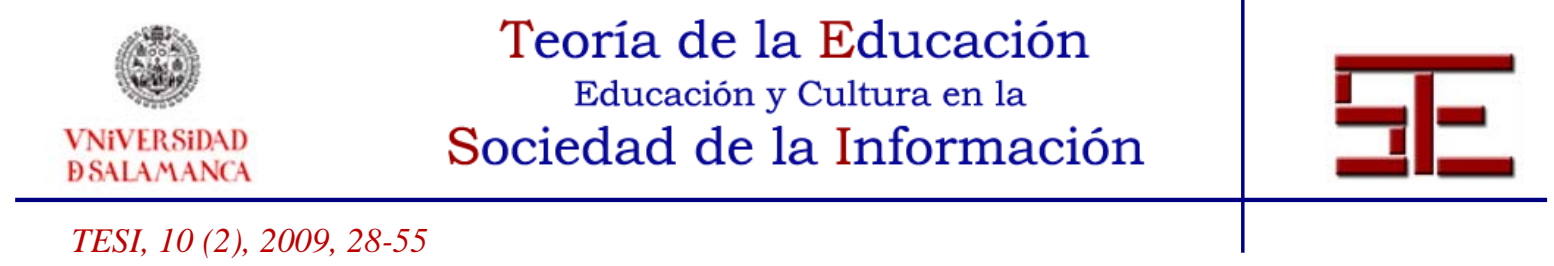

primaria (inicial) ha de documentar el conocimiento tácito o implícito en la empresa o la organización. Lo cual exige diferenciar hechos e interpretaciones. Además ha de establecer un vocabulario común, un lenguaje natural propio; y los procedimientos y procesos han de estar normalizados, es decir escritos los criterios que se consideran adecuados; ha de definirse un sistema de información propio (intranet); y marcar una estrategia hacia la cultura corporativa (Mateos, 2001).

Una vez fijada la dirección estratégica, esta dimensión se ocupa del desarrollo de los planes adecuados tanto a corto como a largo plazo, para alcanzar los objetivos fijados.

Los errores en la planificación significan planificación para errar. La Política de la organización ha de estimular los planes de educación permanente dotándoles de la infraestructura necesaria para desarrollar sus proyectos y programas. El Plan Estratégico de formación por tanto es necesario pero no suficiente. La formación además debe dotar a los miembros de la organización de metodologías cognitivas suficientes como para poder proyectar un futuro a más largo plazo.

La filosofía de la Gestión del Conocimiento manifiesta en sus principios metodológicos que el contenido del conocimiento que anida en las personas y la organización empresarial es fuente de ventaja competitiva. Los formadores tienen la responsabilidad de la emergencia y actualización de dicho tesoro. Es cierto que el conocimiento reside en los individuos, pero los formadores han de establecer las estrategias necesarias para: la identificación, captura, recuperación, compartimiento y evaluación del conocimiento empresarial o de la organización. El objetivo ha de ser que todo conocimiento que reside en la organización pueda ser utilizado por quien lo necesite en el momento oportuno para actuar de forma adecuada (Flores, 2000). La distinción entre tácito (implícito) y explicito se debe a M. Polanyi (1975). El correlato pedagógico insistimos es entre currículo oculto o explicito. El texto o documento tácito es aquel que no está expresado. Sabemos cómo se hace una cosa pero no lo sabemos expresar por escrito. El reconocimiento del conocimiento implícito o tácito requiere ineludiblemente la comunicación con todos los agentes que pueden aportarlo, especialmente con los propios miembros de la empresa y la organización (trabajadores). Un caso particular puede ser el desarrollo de bases de datos de expertos de la propia organización. Debemos enfatizar la importancia del conocimiento implícito (López-Barajas Zayas, 2006, 253).

El conocimiento, por otra parte, es explícito cuando está expresado en algún medio, escrito u oral. Los documentos como tal ya elaborados son conocimientos explícitos.

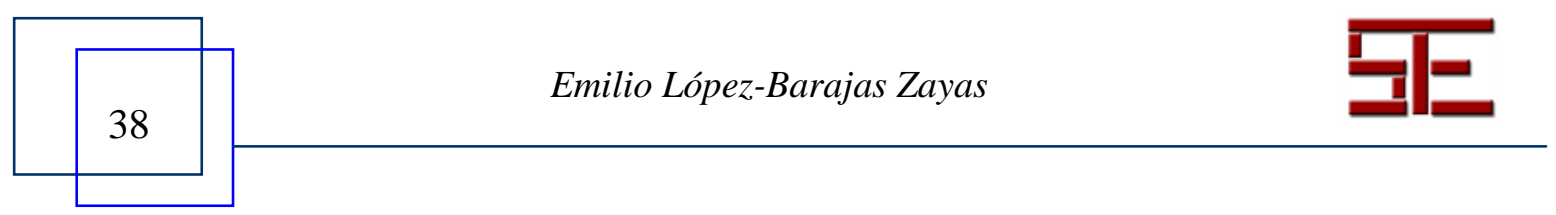




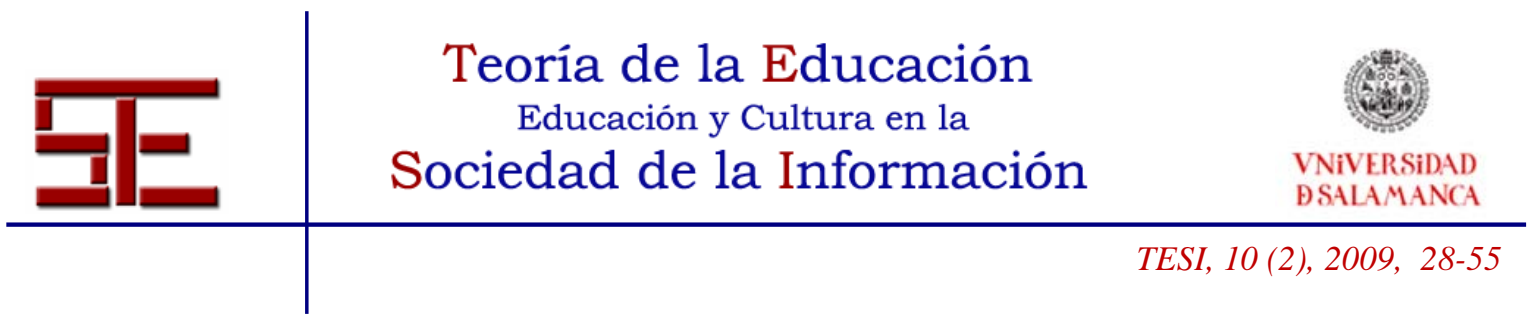

Los manuales de instrucciones o las páginas web son ejemplos, aunque también pueden serlo una imagen o diagrama. La finalidad del conocimiento explícito es la plasmación del mismo.

El proceso por el que se hace efectiva la documentación se llama exteriorización. La exteriorización que supone documentar tareas, o problemas y soluciones de forma comprensiva para todos no es un procedimiento sencillo. Sobre todo si tenemos en cuenta que la interiorización es una actividad subjetiva. Por esta razón los modos de construcción de los documentos es tarea relevante. El documento ha de ser validado, especialmente por los directores, antes de ser colgado o anexado.

Los procedimientos de generación para la exteriorización del conocimiento pueden ser los siguientes (Medrano y Suárez, 2001):

a. Manual: narración del modo sencillo de acceso a la herramienta.

b. Automática: tipo grabadora, que recoge de forma simultánea una forma de “copia”.

c. Circuito de workflow. Un caso particular donde se analiza y especifica unas notas en relación con un problema, las causas y las soluciones.

Los procedimientos de búsqueda para la interiorización del conocimiento son los siguientes:

a. Contextual: aparecen ayudas contextuales en cada circunstancia.

b. Búsqueda guiada: orientaciones hacia el objeto.

c. Mediante tecnología de Internet: indexado general (indexados web).

d. Acceso por navegación en estructuras fijas: establecidas en Intranet.

e. Mapa de relaciones: relaciones de interés.

\section{5.-VIRTUALIZACIÓN METODOLÓGICA PARA LA ALFABETIZACIÓN Y EL CONOCIMIENTO}

La metodología tiene en cuenta obviamente las competencias genéricas y específicas que son propias en cada organización concreta. No obstante, podríamos decir que establecer un Sistema de Gestión del Conocimiento general, y de forma particular desde la perspectiva de la formación, aconseja seguir un proceso suave y gradual de implementación.

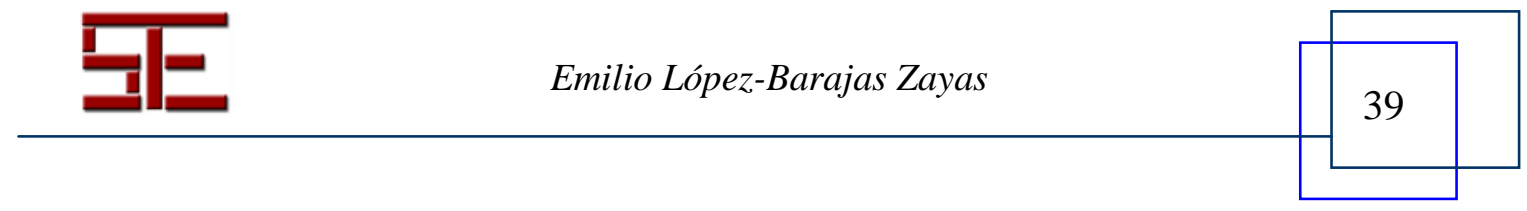




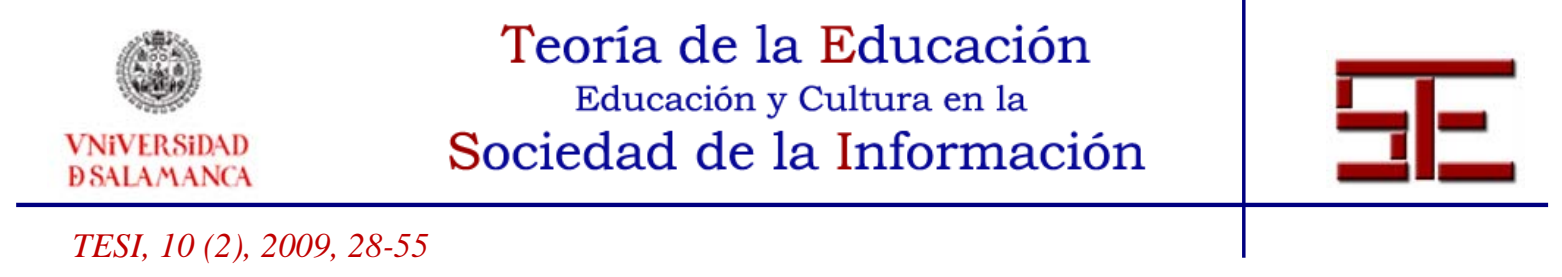

Ha de existir, en todo caso, un responsable, coordinador, o director del Servicio Informático, o si se prefiere de División digital, o Acciones Digitales. En primer lugar se deben realizar experiencias parciales en los diversos niveles de la organización a modo de estudios piloto, con objeto de retroinformar el sistema. Las divisiones, filiales, departamentos o secciones (facturación, gestión de instalaciones, mantenimiento, venta...), control de productos o servicios, proveedores, clientes, distribuidores, etc. Deben estar representados, y tener la dotación del material informático adecuado. Lo conveniente es que en estos estudios o experiencias parciales se incorporen una muestra representativa de lo que es la empresa y la organización. Consideramos que en la planificación estratégica de la formación deben considerarse al menos en su diseño, además de la perspectiva de la división de Recursos Humanos, la propia financiera (consideración de la variable valor añadido de formación), los clientes (grado de aceptación del producto o servicio), los procesos (calidad total), e infraestructura e innovación (grado de mejora sostenible de la formación que se imparte) (López-Barajas Zayas, E., 2006).

Un modelo modificado, que sigue el esquema conceptual del análisis de contenido, y que puede resultar práctico, es el siguiente (Medrano y Suárez, 2001):

Fase $1^{\text {a: }}$ Se trata de la identificación, a modo de "estructura sistémica” para documentar el conocimiento, de las categorías (y las variables, y factores o valores dentro de ellas) que son relevantes a la naturaleza y estructura concreta de cada empresa y organización. La especificación taxonómica de las categorías es decisiva. El producto final será: El Estatuto escrito de la Gestión del Conocimiento.

Fase 2a: Selección de las fuentes de información. Deben ser incorporadas fuentes con naturaleza interdisciplinar: tecnológica, pedagógica, psicológica, de la información, etc. El trabajo final debe concretar las más relevantes para la empresa en general, y las especificas acerca de la formación.

Una clasificación de tipologías generales que puede ser tenida en cuenta es la siguiente (Medrano y Suárez):

a. Sistemas transaccionales (gestión de adquisiciones, gestión de ventas, gestión de proyectos, contabilidad, nóminas).

b. Sistemas de información estructurada (registro general de documentos, registros de curricula, herramientas colaborativas (agendas, contactos...),

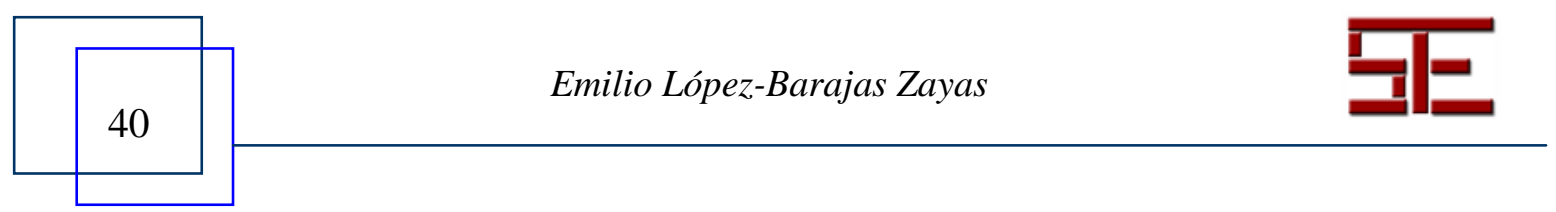




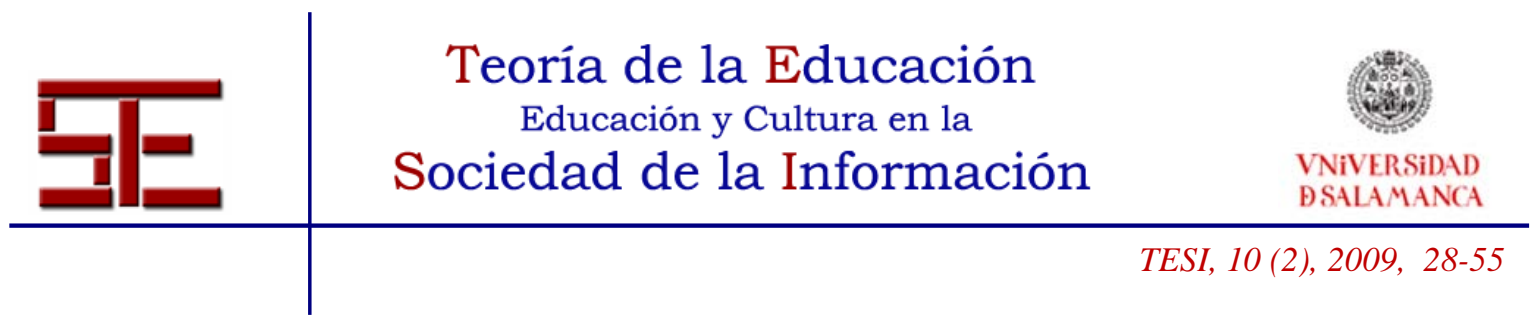

bases de datos especializados: prensa, legislación, programas de gestión de la biblioteca, programa de gestión de archivo.

c. Sistemas de información no estructurada: enlaces a recursos de Internet, comunidades virtuales, informes externos (estudios de mercado, análisis de competencia...).

d. Herramientas de generación de informes: las propias del sistema de información existentes, data mining, dataware house, inventario y catálogo de archivos, catálogo de la biblioteca.

Fase $3^{\mathrm{a}}$ : Establecer una regla que permita asignar los conocimientos encontrados, (como gotas de agua que se convertirán en corriente caudalosa), a las categorías establecidas. Anotando cuando sea posible a que variable o factor corresponden. La regla debe advertir que las diferentes versiones (informaciones precedentes acerca de los problemas o carencias; o potencialidades) que se refieran a resolución de problemas con clientes o usuarios deben ser tenidas en cuenta. Las diferentes perspectivas de los agentes también han de ser consideradas y anotadas. Además se especificará los roles de los que emiten los textos.

Fase 4a: Implantación de la solución tecnológica. Se trata de distribuir en la plataforma digital, aquellas informaciones que han sido relevantes, especialmente sí en el proceso de triangulación (por ejemplo: directivos, clientes, y proveedores) manifiestan coincidencias.

El establecimiento de un sistema de categorías y de conocimientos claves es supuesto necesario, ya que una gran cantidad de información sin un procedimiento de análisis conveniente puede convertirse de solución en nuevo problema.

En suma, a modo de conclusión, la metodología del análisis de la información es muy importante. El análisis de contenido es una metodología sencilla y muy adecuada, en el que se establecen tres fases: unidad de análisis (nota de campo impresa, página web, artículo, libros, etc.), categorías que se consideran básicas en el conocimiento (por ejemplo conocimiento, comprensión, aplicación, análisis y síntesis), y regla para asignar los conocimientos, y datos que se identifican en la organización a esas categorías.

Los agentes son las personas que poseen el conocimiento para lo cual habrá que identificar los contactos oportunos, y establecer grupos de conocimiento, a modo de

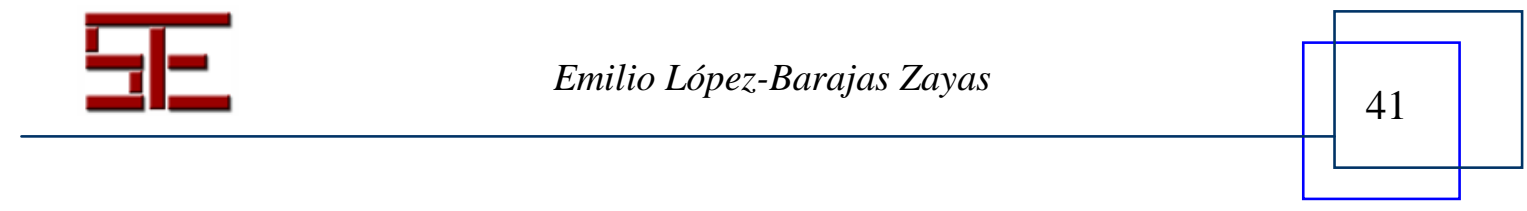




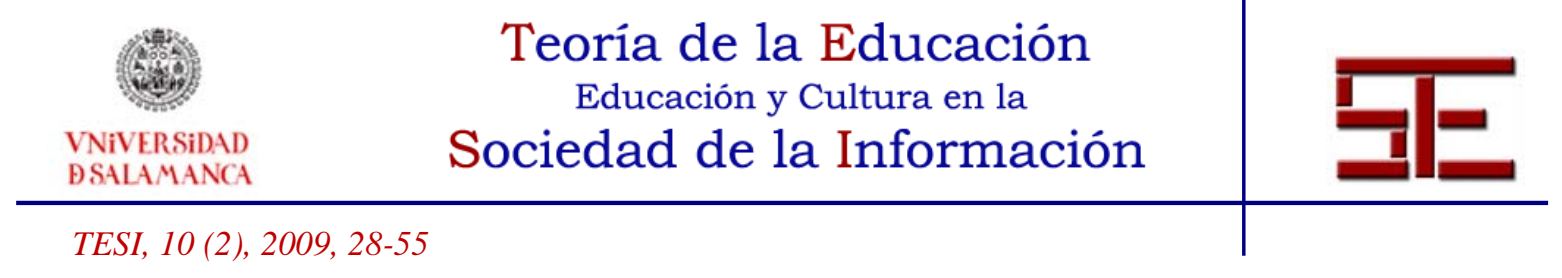

"grupos de calidad", grupos de trabajo mediante las plataformas digitales o simplemente de correo.

\section{6.-POSIBILIDADES Y LÍMITES DE LA RED}

Los formadores han de saber que la innovación cuenta con pocos apoyos, en principio, y por el contrario, el seguir como estábamos con el apoyo de la mayoría. Las dificultades potenciales previsibles que aparecen ante los planes, proyectos y programas de formación tienen un origen muy diferente, pero en general, siempre se identifica con las carencias de cultura corporativa, ya que la cultura predominante es tecnocrática, de naturaleza operativa, de perspectiva ingenieril, pero no participativa, y las inercias sociales suelen ofrecer resistencias al cambio.

La Gestión del conocimiento considera que la categoría aspecto financiero de la empresa y la organización no es la más importante actualmente en la valoración de una institución La categoría o criterio más relevante es la habilidad para ejecutar la estrategia establecida. Se prueba que el $70 \%$ de los fallos no proceden de la estrategia diseñada sino del "como" ha sido ejecutada; con el consiguiente incumplimiento de los objetivos generales propuestos ante los accionistas, los clientes, y los usuarios del sistema (trabajadores) (Flores, 2000). En consecuencia, son exigencias del aprendizaje continuo de la gestión del conocimiento, la alta competitividad del mercado, la convergencia de productos, las agresivas estrategias de precios, los cambios de gustos de los clientes o usuarios, la diferenciación de las necesidades, etc. La respuesta a dichas exigencias es la Gestión del Conocimiento a través de la organización operativa de la red digital de comunicaciones.

Para tener una idea plástica de las posibilidades de Internet en el diseño de la Gestión del conocimiento, "basta imaginarse una red de carreteras en las que hay diferentes vías que van desde caminos vecinales a las más modernas autopistas. Eso explica por qué en ocasiones vamos muy lentos y en otras más rápidos. También influye el coche que tengamos, por supuesto, ése será nuestro equipo (Socorro, 2001). La formación primariamente, hemos de tenerlo claro para no albergar falsas esperanzas, no es una cuestión de técnicas o instrumentos, aun siendo muy importante la calidad de los mismos, sino de forma de ser. Las técnicas de información y comunicación actuales nos permiten la modelización virtual de la formación, y además acceder, no solo al conocimiento del "entorno interior" de la organización, sino obtener información del

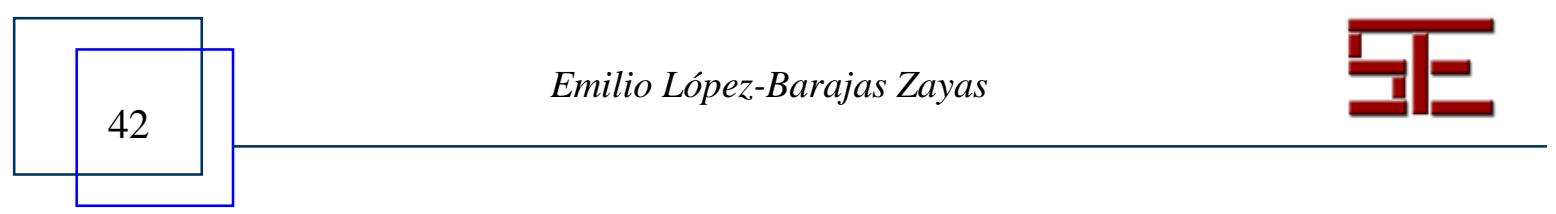




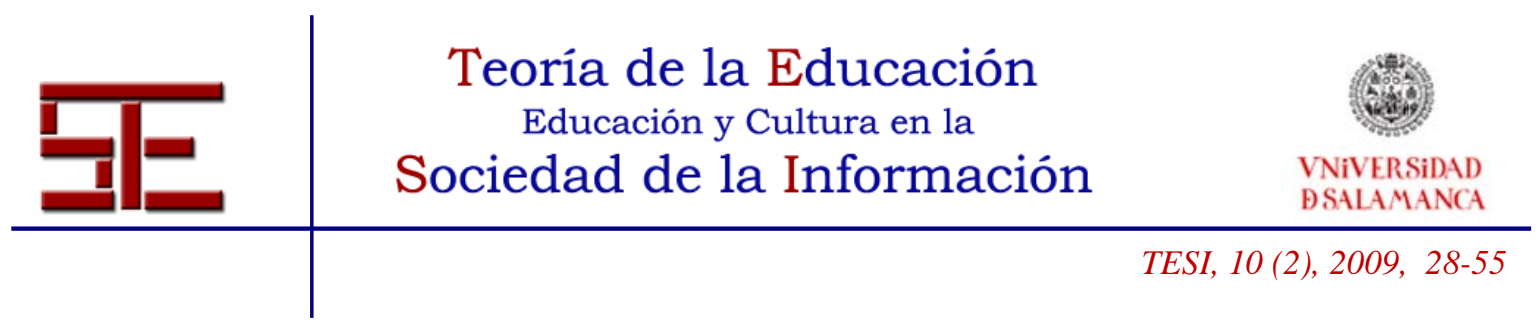

“entorno exterior” donde reside la competencia. La red contiene una inmensa cantidad de información y posibilidades. Para acceder a esta información existen los llamados servicios. Aunque existen otros, aquí sólo mencionaremos los más importantes en la actualidad: WWW, FTP, y correo electrónico. Cada uno de los cuales está basado en un protocolo diferente (Gralla, 1996). Internet es un medio de excepcional importancia con naturaleza, estructura y finalidad propias, en el que todos los agentes pueden participar. La Asociación para la investigación de Medios de Comunicación (AIMC), que lo es sin ánimo de lucro, a través de sus estudios de audiencia, desde 1996, constata que la evolución de los usuarios que tienen acceso a Internet ha sido creciente y en forma notable. En el mundo más de treinta y cuatro millones de personas tienen acceso a Internet. Operativamente se puede definir Internet como una red global de equipos informáticos que se comunican en un lenguaje común. En realidad el formador que se conecta a un sitio Web está en Internet. Lo que denominamos web no es más que las páginas a las que accedemos por medio de navegadores. World Wide Web (el Web o $W W W$ ) proporciona un interfaz gráfico de fácil acceso para buscar documentos de formación relacionados con Internet. En realidad es una red de información. Los hipervínculos tienen una finalidad importante: saltar de una página a otra. La World Wide Web Consortium (W3 Consortium) "desarrolla normas para la evolución de las partes de más rápido crecimiento en Internet, la Worl Wide Web. Se trata de un consorcio industrial gestionado por el Laboratory for Computer Science del Massachussets Institute of Technology que colabora con organizaciones de todo el mundo como el CERN, los precursores de la Web. Sirve como depósito de información sobre la Web para desarrolladores y usuarios, implementa estándares Web, produce prototipos y utiliza aplicaciones de muestra para probar nuevas tecnologías" (European Software Institute, 2003). Los sitios web podríamos decir que son libros o, si se prefiere, un conjunto sistemático de páginas, es decir, que están relacionadas, que forman un sistema dinámico. Las páginas se han de entender en sentido amplio ya que pueden contener además de textos, películas, sonidos, gráficos en tres dimensiones, etc. La página principal es la que aparece al inicio de un sitio web, a modo de lo que sería la cubierta de un libro, o tal vez mejor, su índice. Todas y cada una de las páginas web, incluida la principal, tienen una dirección URL (Universal Resource Locator). Las herramientas que se utilizan para ver páginas web se llaman exploradores. Los hipervínculos permiten haciendo clic sobre ellos que aparezca un texto o una gráfica, y eso es posible, porque tienen incrustadas otras direcciones URL. El explorador a través de los hipervínculos permite ir de una página a otra diferente. Como auxiliares aparecen en los exploradores: barras de herramientas, de direcciones; además de ayudas contextuales, para buscar, detener, o abrir Favoritos y agregar Favoritos.

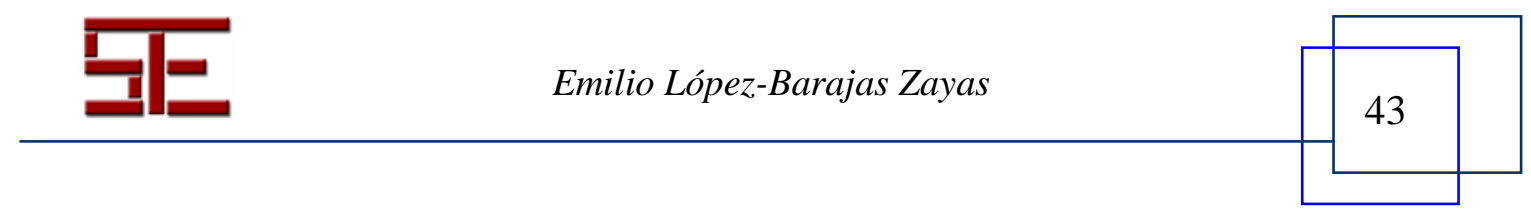




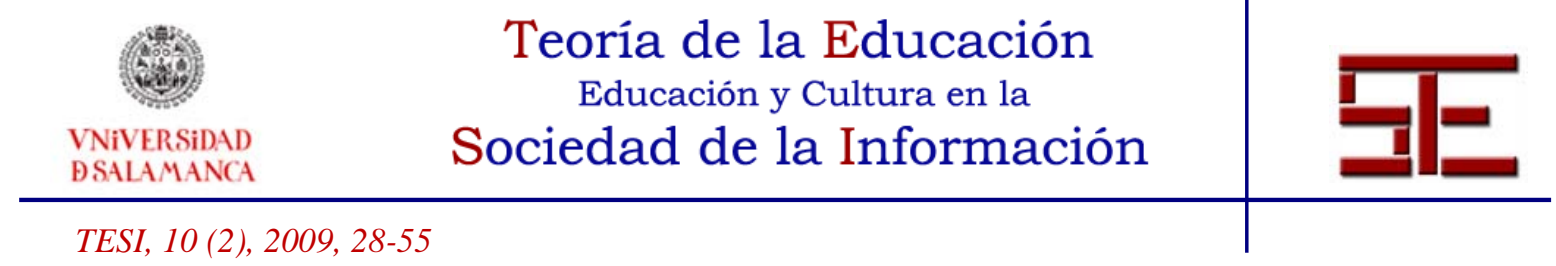

La creación de un acceso directo de una página en su escritorio, permite cuando se crea un archivo de acceso directo, guardarlo en una carpeta, depositarlo en la "estructura sistémica” diseñada en cada organización, o enviarlo a sus colegas o alumnos mediante correo electrónico. Habrá que saber que el tráfico de Internet, no obstante, puede hacer difícil la exploración repentizándola. Esto ocurre porque no todos los servidores son iguales, algunos no tienen capacidad para responder a todos los exploradores, por lo que hay que tener algo de paciencia, y esperar. La velocidad de un módem también es importante, deberá ir al menos a 144000 bps (se duplicaría la velocidad sí fuese a 28800vps). Por último, el formador debe saber que los archivos excesivamente grandes tardan en abrirse y lo hacen con dificultad. La popularización de Internet produjo, no obstante, entre otros, "el fenómeno de que cuanta más información se publicaba y se ponía a disposición de los usuarios, tanto más aumentaba la sensación de "estar perdido" entre tantos datos, a los que no se podía acceder más que conociendo de antemano sus direcciones específicas” (Socorro, 2001). La formación deberá incluir en sus programas de formación en la organización el aprendizaje de los procedimientos más adecuados de búsqueda en cada caso.En la actualidad existen diversos grupos que intentan diseñar el crecimiento de Internet ayudando a establecer estándares e instruyendo a los usuarios sobre el uso apropiado de ésta. Algunos de estos grupos importantes es la Internet Society, un grupo privado que trabaja sin ánimo de lucro. Esta organización respalda el trabajo del Internet Activities Board (IAB), que se encarga de gran parte de las cuestiones ocultas y arquitecturales de Internet. La función de Internet Research Task Force del $I A B$ se centra en la tecnología de redes. El IAB es también responsable de asignar direcciones de red IP a través de Internet Assigned Numbers Authority. Además, gestiona el Internet Registry, que, a su vez, administra al Domain Name System y se encarga de asociar nombres de dominios con direcciones IP" (Socorro, 2001).

El término multimedia, habrá que decir en cuanto a su significado, proviene del término inglés multimedia. Palabra que está compuesta de multi + abreviatura de mass - media. Se puede definir diciendo que es un conjunto de recursos o medios técnicos que sirven para la comunicación. Los multimedia tienen un gran valor pedagógico porque responden al principio de la intuición: mostrar lo que se desea aprendan los alumnos.

Los multimedia están destinados de hecho a la difusión por varios medios de información y comunicación, no obstante, se abren paso en la formación. Ni olvidar que son solo un recurso valioso. Los multimedia, así pues, en forma habitual, son sistemas

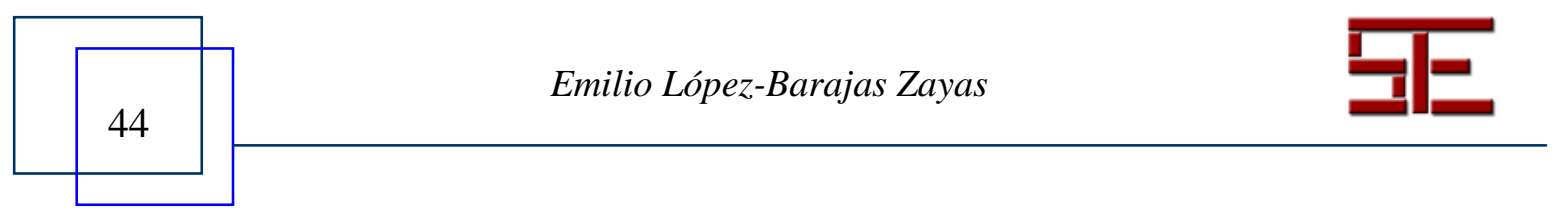




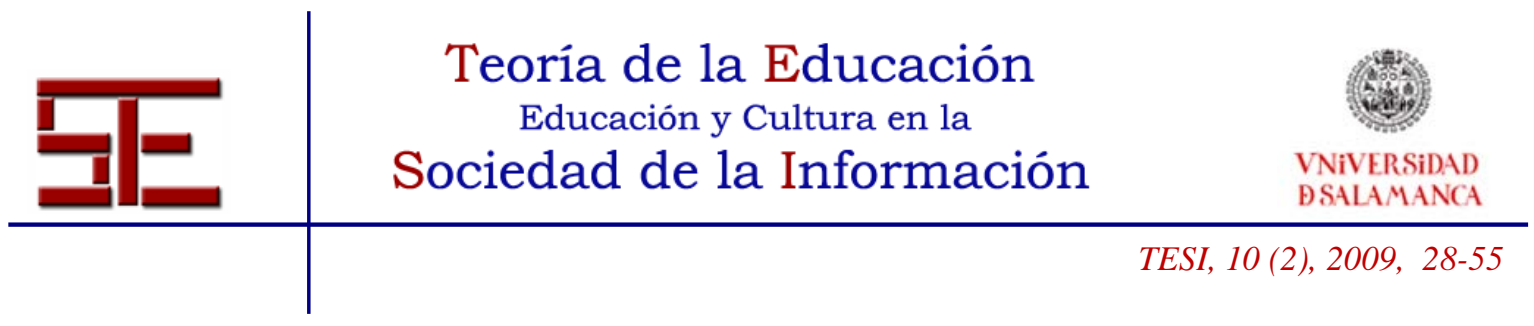

de información integrados de audio, video y datos. El término "superautopistas", que va asociado al de multimedia, se popularizó a través de los planes de la administración Clinton y Gore, cuyo objeto era liberalizar los servicios de comunicaciones, al permitir la integración de todos los aspectos de Internet: CATV, teléfono, empresas, ocio, proveedores de la información, educación, etc. (López-Barajas Zayas, 2006). Hemos de hacer una observación, antes de seguir adelante, respecto del desarrollo de los soportes multimedia: "en 1999 todas las herramientas y métodos de tipo Computer Based Training o CBT quedaban englobas en un solo grupo, pero en los años siguientes los responsables de elaborar informes han sentido la necesidad (bajo la presión de las nuevas prácticas formativas- de desglosar más detalladamente los distintos grupos de recursos multimedia: CD-ROM, Internet, e Intranet.” (Gralla, 1996).

Los educadores hemos de saber que el mercado que se ofrece a la formación virtual es considerable: "En 1997 el mercado estadounidense de Web Based Training dirigido a las empresas se estimó en 200 millones de dólares. La cifra prevista por Internacional Data Corporation para el año 2002 es elocuente: 5.500 millones de dólares, es decir: un aumento medio del 94\% anual" (Acevedo, 1998). Las posibilidades son enormes en el entorno, así "Pearson, por medio de su filial francesa Les Échos, ha puesto en marcha desde hace unos años una verdadera estrategia editorial multimedia, multisoportes y multiobjetivos que, aunque va más allá del marco de la formación, nos permite apreciar claramente la dimensión de esta visión” (Gil, 2001, 46). Los nuevos sistemas multimedia de formación hacen posible volver a centrar la formación desde el diagnóstico inicial del que aprende, y por tanto sería posible graduar los objetivos específicos y los contenidos, además de acompasar los modos y estilos cognitivos del aprendizaje de cada discente.

El modelo curricular está cambiando de forma acelerada: la formación justa, en el momento justo para cada año, según su nivel y su modo de aprendizaje preferido. Entre todo el arsenal de nuevas herramientas, parece que la Web Based Training (o formación virtual a distancia, vía redes de Internet o la Intranet) va a cumplir una función fundamental; especialmente, porque elimina la limitación física de la presencia y ayuda a reducir costes logísticos.

Las posibilidades y límites de la formación, en suma, el aprendizaje basado en la Web se determinará por la calidad de los tres componentes básicos del el diseño de Gestión del conocimiento (Gil, 2001, 119):

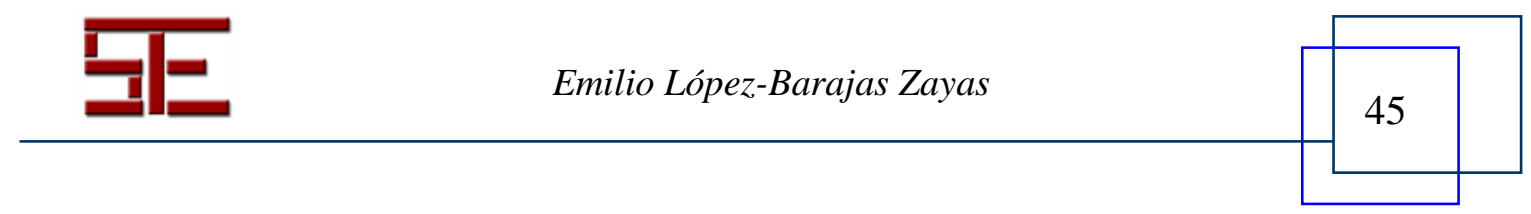




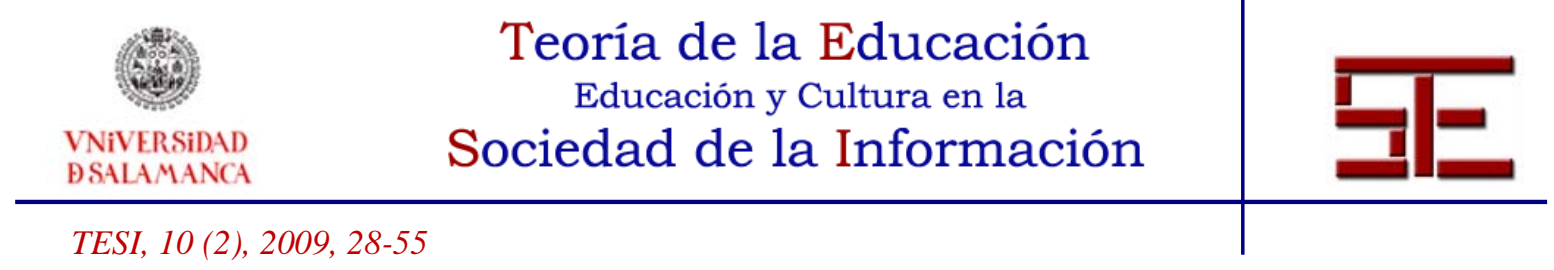

a. "Un componente tecnológico que integra y aglutina las herramientas e instrumentos necesarios para su buen funcionamiento, ya se trate de elementos materiales o de software. Es el campo propio de los técnicos.

b. Un componente organizativo que permite explotar el sistema técnico en base a la estrategia de formación adoptada y permite establecer los modos de aprendizaje adecuados a las necesidades de formación, ya sean generales, masivos, específicos o individuales. Es el campo propio de los directores.

c. Un componente pedagógico que ofrece contenidos, situaciones, trayectorias de formación y la mediación humana. Es el campo propio de los pedagogos".

\section{7.-UN MODELO PARA LA ALFABETIZACIÓN DE LA CALIDAD}

El modelo se refiere a la empresa u organización en su conjunto, pero los formadores hemos de saber que la formación se enmarca en la División o Departamento de Recursos Humanos, y éste en el marco de la organización general de la empresa. Es decir, las demandas de formación se originarán en todos los niveles y áreas de la organización de la empresa, desde los equipos y las personas. La importancia del modelo destaca la planificación estratégica de la formación continua.

Al educador social, ya sea en organizaciones formales o no formales, le interesa establecer algunas normas o criterios que permitan objetivar la información. Los estilos de decisión por parte de los líderes o directivos son fundamentales, y por tanto tarea de formación para los formadores. Algunos estilos que se consideran predeterminados y que fueron sistematizados por Vroom y Yetton fueron los siguientes (1973) (Cfr. En Mateos, 2001, 457-458):

A1 Soluciona el problema o toma la decisión individualmente y con la información con que cuenta en ese momento.

A2 Obtiene de su (s) subordinados (s) la información precisa y después decide de forma individual (puede comunicar o no a los subordinados la naturaleza del problema).

C1 Comparte el problema con sus subordinados de forma individual y recibe de aquellos las sugerencias e ideas que le pueden ayudar a tomar la decisión.

C2 Comparte el problema con sus subordinados como grupo y recibe sugerencias que le pueden ayudar a tomar la decisión.

G2 Comparte el problema con sus subordinados como grupo y elabora con ellos las alternativas, buscando un consenso (sin influir en el grupo) acerca de la solución.

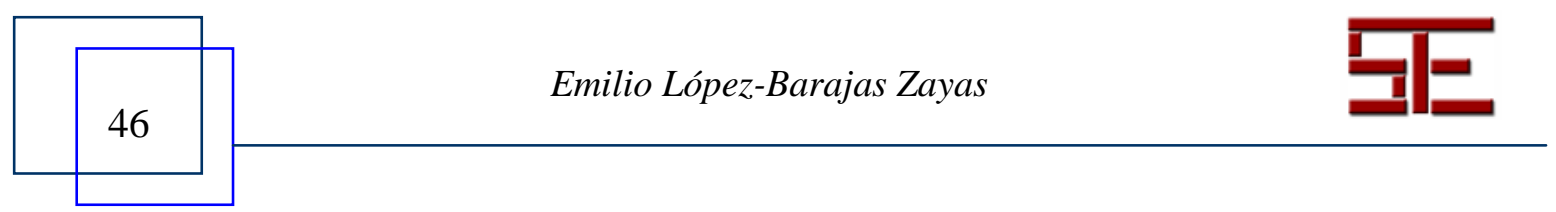




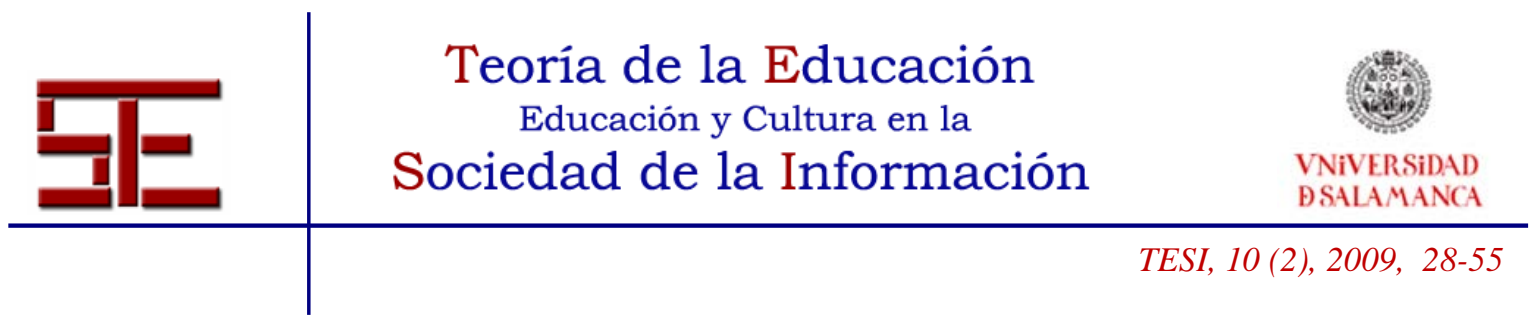

Las directrices de formación, en cada entorno, también pueden contemplar estas posibilidades de naturaleza general, en cuanto a estilos de decisión que deberán formar parte de la cultura de la empresa en todos sus niveles. Destacamos, no obstante, desde la perspectiva pedagógica la toma de decisiones consensuada, donde todos los agentes sociales toman parte.

La educación permanente ha de desarrollar, además, atributos o cualidades positivas. Los autores señalados concretaron siete caracteres. Los siete atributos relevantes que en su día establecieron Vroom y Yetton para la elección del estilo de decisión, y que son la base de su modelo normativo son (Cfr. en Mateos, 2001, 457-458):

a) La importancia de la calidad de la decisión.

b) El grado en el que el líder posee suficiente información / destreza, para llegar por su cuenta a una decisión de la calidad elevada.

c) El grado en el que el problema está estructurado.

d) El grado en el que la aceptación o el compromiso por parte de los empleados de su responsabilidad (subordinados) es crítico para la puesta en práctica eficaz de la decisión.

e) La probabilidad previa de que la decisión autocrática del líder reciba aceptación por parte de sus subordinados.

f) El grado en que los subordinados están motivados para alcanzar las metas de la organización, tal como están representadas en los objetivos explícitos del planteamiento del problema.

g) El grado en que es probable que los subordinados entren en conflicto respecto de las soluciones encontradas.

Además de las características se deberían establecer algunas normas. Las reglas que permiten el establecimiento de la credibilidad de la información son, según dichos autores, las siguientes:

$1^{\text {a) }}$ Regla de la información. Si la calidad de la decisión es importante y el líder no posee suficiente información o destreza para resolver el problema por su cuenta, A1 se elimina de las posibilidades factibles.

$2^{a}$ ) Regla de la congruencia. Si la calidad de la decisión resulta importante y los subordinados no comparten las metas de la organización que se alcanzaran con la solución del problema, G2 se elimina de las posibilidades factibles.

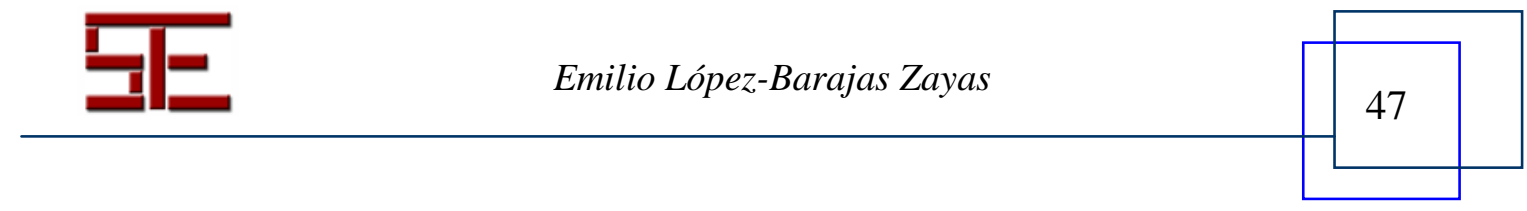




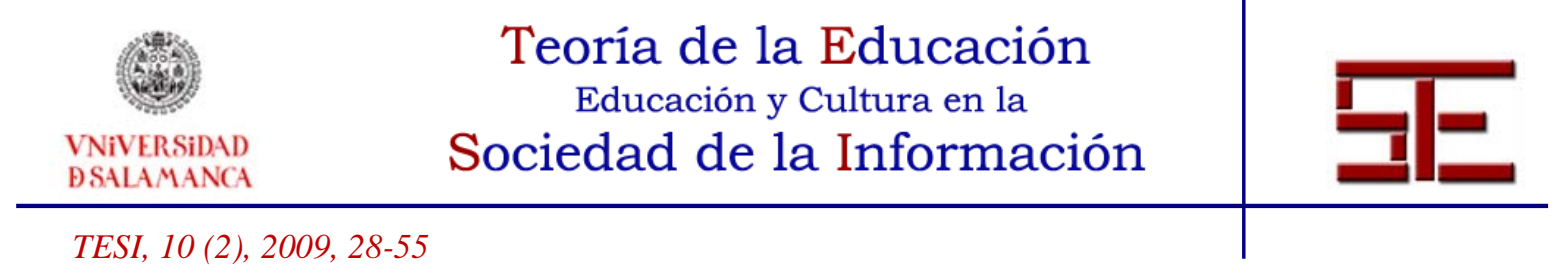

$3^{a}$ ) Regla del problema no estructurado. En las decisiones en las que resulta importante la calidad, si el líder carece de la información, o de la destreza necesaria para solucionar el problema por su cuenta, y si el problema no está estructurado, el método empleado debe prever no sólo que él reúna la información, sino que lo haga de manera eficiente y eficaz. En estas condiciones $\mathrm{A}_{1}, \mathrm{~A}_{2}, \mathrm{y} \mathrm{C}_{1}$ se eliminan de la serie factible.

$4^{a}$ ) Regla de la aceptación. Si la aceptación de la decisión por parte de los subordinados resulta crítica para su aplicación eficaz, y no es seguro que una decisión autocrática tomada por el líder vaya a tener esa aceptación, A1 y A2 se eliminan de la serie factible.

$\left.5^{a}\right)$ Regla del conflicto. Si la aceptación de la decisión es crítica y no es seguro que vaya a aceptarse una decisión autocrática, y es posible que los subordinados se encuentren en conflicto o en desacuerdo acerca de la solución apropiada, A1, A2 y C1 se eliminan de la serie factible.

$6^{a}$ ) Regla de la equidad. Si la calidad de la decisión no resulta importante y la aceptación es crítica, al tiempo que no es seguro que resulte de una decisión autocrática, $\mathrm{A}_{1}, \mathrm{~A}_{2}, \mathrm{C}_{1}$ y $\mathrm{C}_{2}$ se eliminan de la serie factible.

Las reglas podrían sufrir algunos enunciados más pero en cualquier caso siempre resultará formativo contemplar alguna sistemática de las mismas.

Habrá que decir, finalmente, que el desarrollo tecnocientífico propio de la Sociedad del Conocimiento, debe abrirse al horizonte de los valores pragmáticos hacia los ontológicos, sustantivos esenciales, donde las personas y las organizaciones pueden anclar un desarrollo sostenible y más justo.

\section{8.-CONCLUSIONES Y PERSPECTIVAS FUTURAS}

El futuro del aprendizaje y la formación permanente será de los “mundos virtuales”. El significado de "mundos virtuales" es referido semánticamente a MUVEs (Multi-User Virtual Environments), es decir nos referimos a Entornos Virtuales de Múltiples Usuarios, que acceden a los mismos a través de Internet, facilitando la interacción de los mismos y la comunicación, que se produce en un entorno de polígonos isométricos que construyen la ilusión de un espacio tridimensional. Las transformaciones isométricas

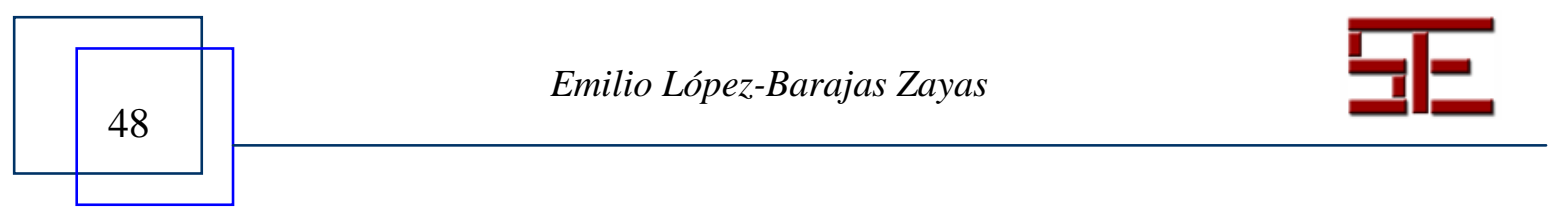




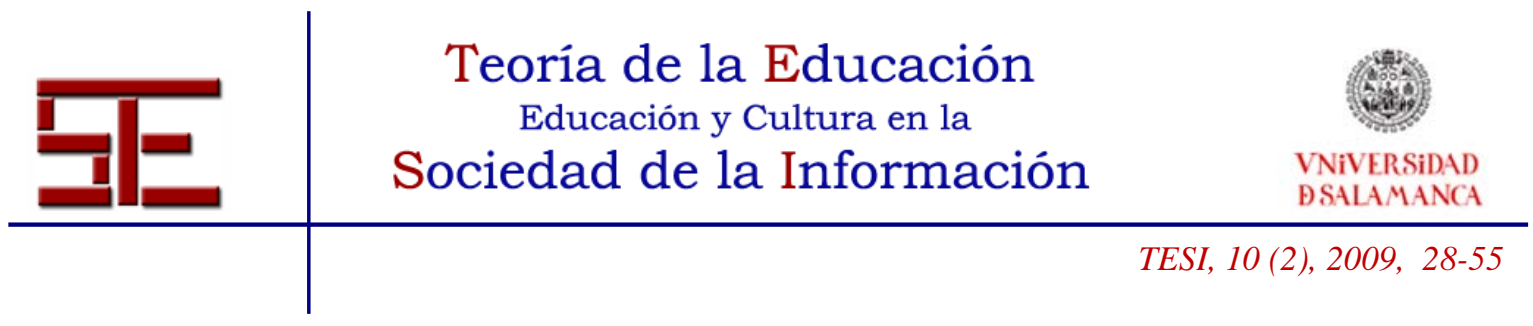

son de las figuras en el plano que se obtienen sin variar las dimensiones ni el área de las mismas, por cuya razón la figura inicial y final son semejantes, y geométricamente congruentes.

La creación en 1994 del lenguaje VRML permitió que los entornos 3D fuesen interactivos, y pudieran ser utilizados on line lo que permitió que la metodología avanzara por sus dos vertientes: la didáctica y la heurística. Se hacía posible "el mundo virtual real". Las novedades de software y el trabajo de algunas instituciones, que se aplicaron al desarrollo de proyectos, hizo posible el avance didáctico y tecnológico. Entre otros pueden señalarse los siguientes: MIT (Massachussets Institute of Technology), la Universidad de Carolina del Sur, la Universidad George Mason, la Universidad de Nottingham, la Universidad Abierta de Inglaterra, la Escuela Superior de Informática de Georgia, la Universidad Virtual (Consorcio), la Universidad de Ohio, etc.

La idea del MUVE ha existido desde finales de los 80 del siglo pasado. El término se le atribuye a Chip Morningstar, co-creador del famoso juego de rol online Habitat desarrollado por Lucasfilm y que marcó el inicio de los MMORPGs (Massively Multiplayer Online Role-Playing Game), un género de videojuego, como es sabido de todos, en el que un gran número de jugadores interactúan, en el escenario de un "mundo virtual”. El interés que suscitan los juegos permite considerar que la motivación será patente si los procesos de aprendizaje virtual se desarrollan a través de estos recursos didácticos. La industria World of Warcraft y Everquest es otro ejemplo de proyecto que supone un negocio próspero dado la motivación que producen sus productos en el usuario.

Los entornos 3D, por tanto, cabe considerarlos como prestaciones de networking social y formativo, cuyas "herramientas" de colaboración son de naturaleza online. Uno de los entornos 3D más populares y conocidos, sin duda alguna, es Second Life (SL), una plataforma de mundo virtual que propicia básicamente la interacción social de los usuarios. Second Life es un mundo virtual 3D que nació en 2003 y ahora tiene, sorprendentemente, cinco millones de miembros en todo el mundo. Más que un juego con objetivos definidos, es una "realidad vital virtual" donde sus residentes conviven, charlan, trabajan, se motivan, y aprenden en este mundo virtual. Escuelas y universidades latinoamericanas y españolas están empezando a crear "experiencias de comunidades" dentro de Second Life. La comunidad Active Worlds Educational Universe (AWEDU) permite que esta plataforma pueda utilizarse para propuestas

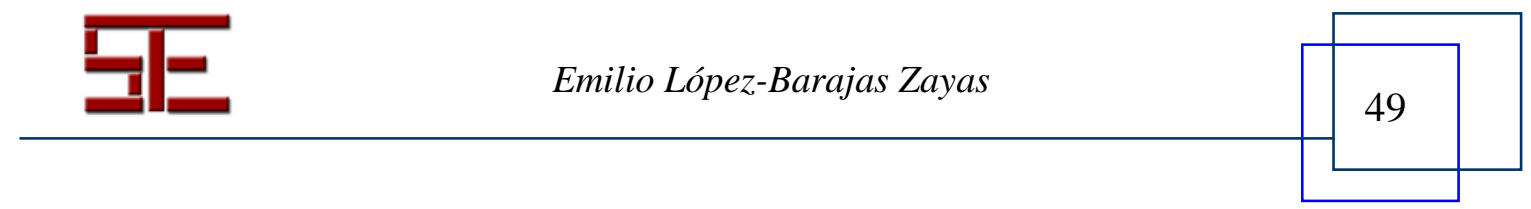




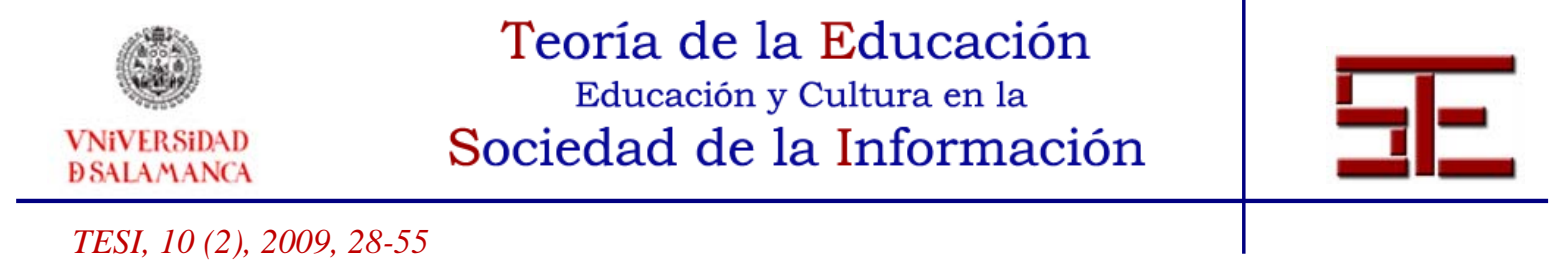

educativas. Pablo Manzini, define a la modalidad virtual de SL como un entorno de "arquitectura abierta, de interacción física y cognitiva", en el cual la interacción no se da tanto con la interfaz del mismo como a través del análisis del contenido de la información, y además, la comunicación entre los usuarios de la red (www.pablomancini.com).

También es posible, en la actualidad, la integración de $S L$ como herramienta de naturaleza didáctica, que responde al principio educativo de la socialización, y la actividad, con plataformas de e-learning libre como es Moodle, lo que aumenta las posibilidades didácticas, en el supuesto de llevar a cabo un proyecto o programa educativo, un ejemplo que puede citarse es el Proyecto SLoodle. Existe la posibilidad de establecer programas de formación, con alumnos entre 13 a 17 años en la modalidad denominada: Teen Second Life (TSL). Linden Lab patrocinador de SLEDT listserv para educadores que trabajan con adolescentes en TSL, lo recomienda a los educadores que quieren trabajar en este nivel cronológico TSL, y que se enrolen en la lista SLEDT, donde podrá aprender de forma "real" algunos proyectos con adolescentes, a modo de un estudio de casos.

La plataforma Vastpark facilita, como experiencia comercial, la creación de contenidos de aprendizaje en tres dimensiones. La Plataforma Dotman hace posible un entorno virtual de intercambio de experiencias y promoción de las organizaciones de sus negocios reales. Se destina principalmente hacia el área china. El entorno denominado SmartMeeting, de naturaleza colaborativa en 3D ofrece a las organizaciones y usuarios la posibilidad de señalar un calendario de reuniones con el propósito de , debatir cuestiones de interés, a través de un sistema de videoconferencia, servicios acerca de como navegar por la Web, compartir documentos, reproducir archivos multimedia, etc.

El grupo IL3 de la Universidad de Barcelona, apoyándose en la experiencia de FactorSIM, comenzó a preparar un curso utilizando Second Life como entorno virtual de formación y aprendizaje. Las ventajas que consideraron en su experiencia fueron las siguientes: a) Muchos alumnos no habían asistido antes a un curso on-line. De una manera bastante autónoma, la mayoría consiguieron entrar en SL, crearse un avatar y superar el miedo inicial; b) la mayoría de ellos consiguen cambiar su apariencia. Un porcentaje relativamente bajo (el 20\%), cambian de forma drástica su apariencia. c) la experiencia inicialmente presentó algo de confusión, ya que muchos alumno esperan unos objetivos concretos a realizar con Second Life. Una vez superado el primer impacto, se muestran muy confiados y capaces de avanzar en el conocimiento del

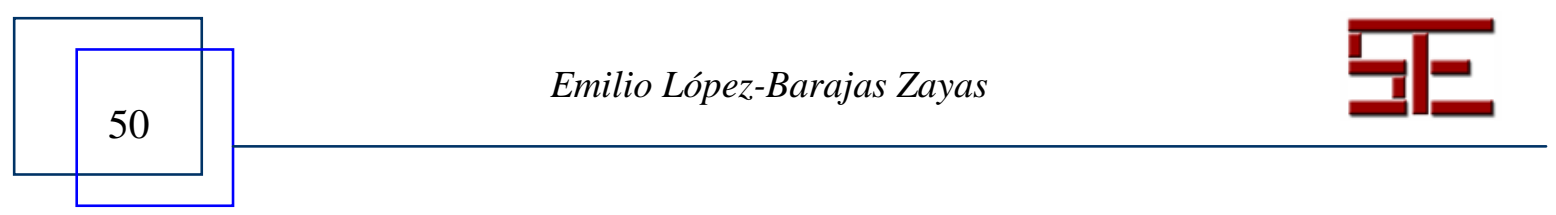




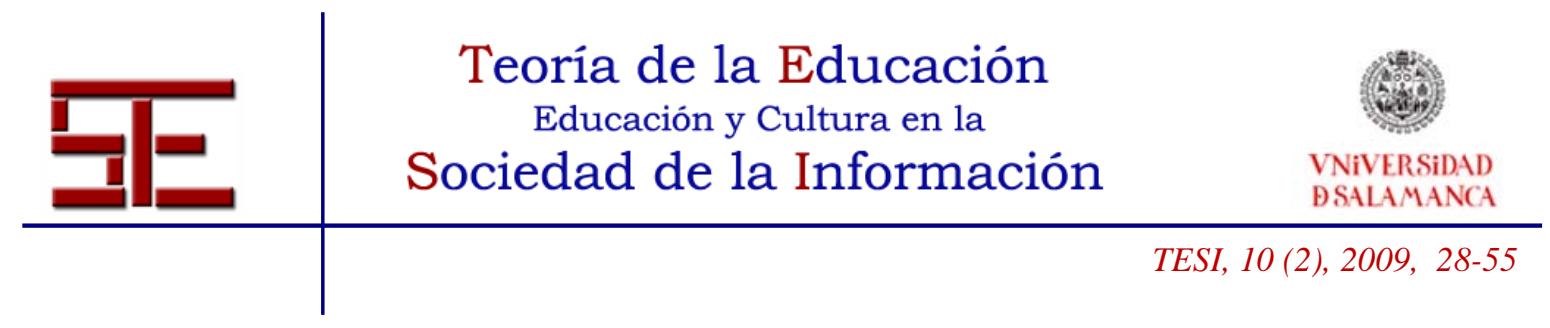

entorno. Aprenden muy rápido. Les cuesta mucho volar y manejar la cámara. d) buscan poseer objetos, ropas y direcciones. Les otorga una falsa sensación de seguridad. e) la comunicación con el tutor y con el resto de alumnos mejora y se potencia después de las sesiones presenciales en Second Life. f) se crea un mayor vínculo y cooperación entre los alumnos una vez realizadas. De hecho, al sentirse todos "perdidos" y en igualdad de conocimientos, se potencia el aprendizaje colectivo y la transmisión de experiencias g) Hay una gran motivación en las clases, en los foros y en las actividades realizadas. Los alumnos que completan el curso muestran una gran satisfacción y consideran que han conocido un entorno nuevo con aplicaciones educativas muy interesantes. A finales de 2008, principios de 2009, está previsto realizar un proyecto piloto de clases totalmente en Second Life, con contenidos adaptados y herramientas personalizadas. Será un proyecto prueba de impacto acotado en alumnos que permita evaluar si el modelo es extrapolable a otros ámbitos de formación dentro de IL3.

El mundo virtual de TAATU, construida hace solo unos años, es casi única en el Mundo Virtual, ofreciendo la posibilidad de combinar animación 3D con la vida real: emisión de TV, sesiones en vivo mediante la cámara web, streaming de música en vivo, accesible paralelamente a miles de usuarios. La finalidad de TAATU, que se desarrolló en Europa, fue el diseñar un espacio virtual moderado y seguro, que permitiese abrir los horizontes de los contactos en el mundo.

La iniciativa de Virtual Educa en Iberoamericana tuvo como finalidad la realización de Proyectos Innovadores en los ámbitos de la Educación, la Formación o Capacitación Profesional y la Formación Permanente.

Las pantallas 3D, no obstante lo señalado, son todavía muy caras y, como siempre, con el paso del tiempo y la demanda, se harán más asequibles. Habrá que decir, finalmente, que los Proyectos de incorporación de aromas o vibración, con objeto de favorecer aun más el aprendizaje lógico, manifiestan una cierta lentitud en sus desarrollos técnicos, por ejemplo, el Sensorama [http://en.wikipedia.org/wiki/Sensorama] que fue desarrollado a principios de los sesenta del siglo pasado.

El aprendizaje virtual, a modo de conclusión final, debe estar presente en esta forma de desarrollos, ya que la mentalidad juvenil apuesta por ella, y éstos son los estudiantes del presente y el futuro.

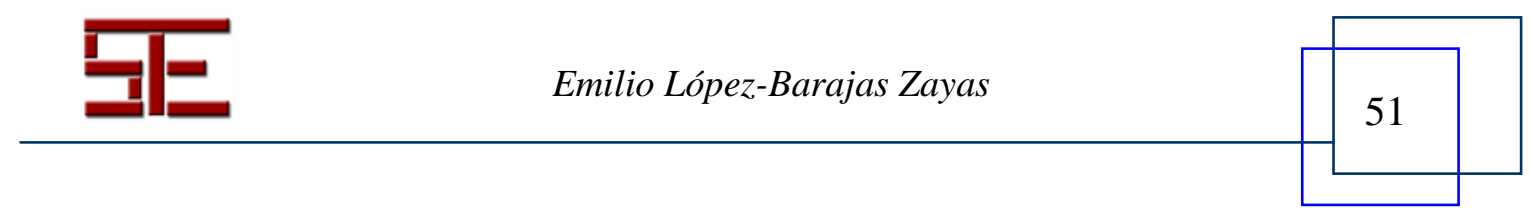




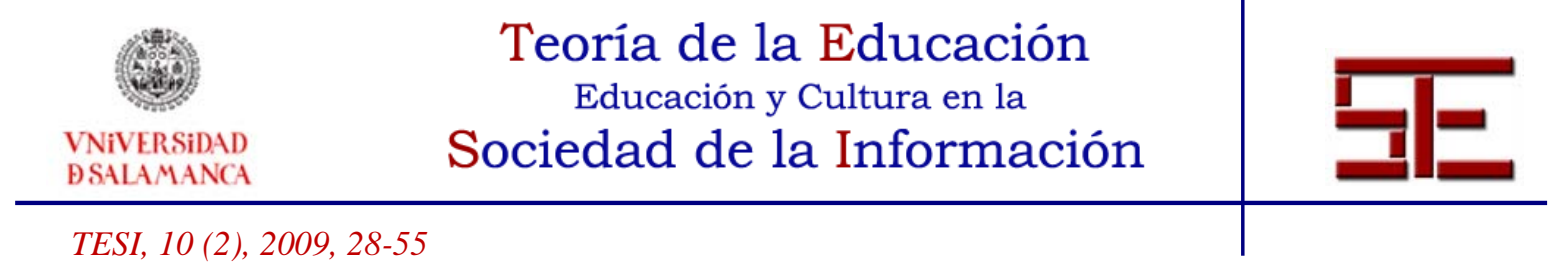

\section{BIBLIOGRAFÍA}

Abadal, E. (2001). Sistemas y servicios de información digital. Gijón: Trea.

Acevedo. F. et. al. (1998). Buscadores de Internet. Madrid: Paraninfo.

Bangay. S. (2001). Experiences in porting a virtual reality system to Java. En The first conference on computer graphics, virtual reality and visualization (pp. 33-37). ACM Press.

F. Biocca, F. P. Brooks, Jr, L. Hodges, K. Mania, M. Meehan, M. Slater, A. Steed, and Whitton, M. (2002). Understanding virtual environments: Immersion, presence and performance. Ponencia presentada en el curso de ACM SIGGRAPH.

Buscaempresas: www.buscaempresas.com.

Asociación Española De Empresas Multimedia: www.asedem.org.

Birkenbihl, M. (1996). Educación permanente. Madrid: Paraninfo.

Brint: http://brint.com

Canals, A. y Perez Gutiérrez, M. (2001). Hacia la Gestión del Conocimiento. Gestión del Conocimiento.com. Extraído de http://www.gestióndelconocimiento.com.

Codina, L. (1999). El libro digital y el territorio de la lectura. Profesional de la Información, 8 (1-2), 4-6.

Cook, J. and Pettifer, S. (2001). Placeworld: An integration of shared virtual worlds. En ACM SIGGRAPH Sketches and applications (p. 243). ACM Press.

Cuatrecasas, L. (2001). Gestión Integral de la Calidad. Barcelona: Gestión2000.com.

Del Pozo Delgado, P. (1997). Educación permanente. Madrid: Pirámide.

European Software Institute (2003). Metodología y software para la construcción y seguimiento del Cuadro de Mando Integral en las TIC’s.

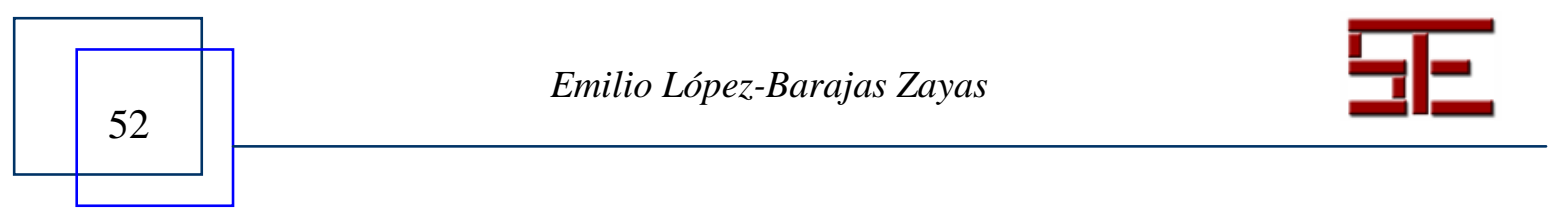




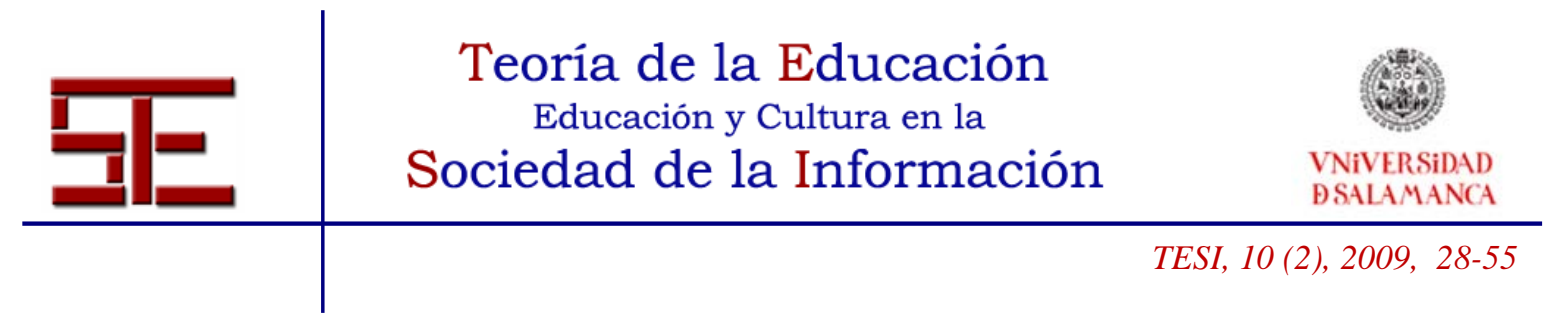

Flores Vivar, J. (2000). Gestión del conocimiento. Gestión del Conocimiento.com. Extraído de http://www.gestióndelconocimiento.com.

García Carrasco, J. (1997). Educación de Adultos. Barcelona: Ariel.

García Carrasco, J. y otros (1999). Nuevas Tecnologías y Formación. PCWEEK, 489, 75.

García Carrasco, J. y García Del Dujo, A. (2001). Teoría de la Educación. T.II. Procesos primarios de formación del conocimiento y la acción. Salamanca: Ed. Universidad de Salamanca.

Garcia Carrasco, J., Garcia, F., López, M., Lopez, R. y Verdú, E. (editores) (2005). Educational Virtual Spaces in Practice. Barcelona: Ariel-EuropeAID.

Garcia Carrasco, J. y otros (2006). Best Practices in E-learning: Toward a Technologiybased an Quality Education. Valladolid: BEM Ed.-EuropeAID.

Garcia Carrasco, J. (2007). Leer en la cara y en el mundo. Barcelona: Herder.

García Marza, D. (1996). La ética como instrumento de gestión empresarial. Barcelona: Universitat Jaume I.

Gestión Del Conocimiento: http://gestióndelconocimiento.com.

Gil, Ph. (2001). E-Formación. Bilbao: Ediciones Deusto.

Gralla, P. y Ishida S. (1996). Como funciona Internet. Madrid: Pretice Hall Iberia.

Infonomia: http://www.infonomía.com.

Herreros, C. (2000). Aprendizaje, cambio y cultura. HFC Consultores, S.L. Gestión del Conocimiento.com. Extraído de http://www.gestióndelconocimiento.com.

Kerzel, D. y Hecht, J. (2001). Visual causality. En M. May and U. Oestermeier, editors, Interdisciplinary perspectives on causality (pp. 119-139). Books on Demand.

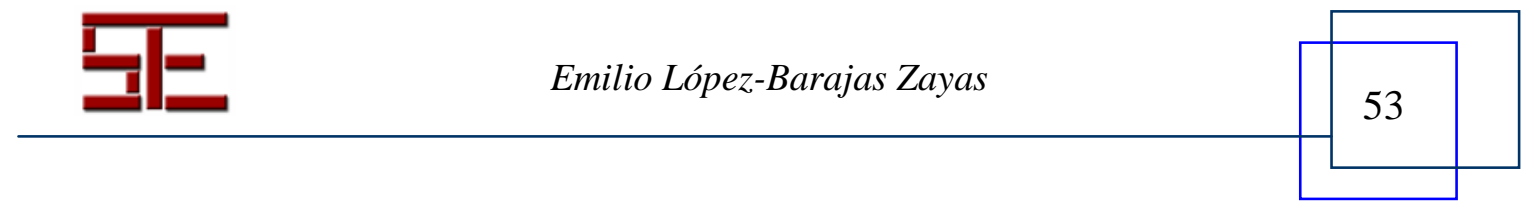




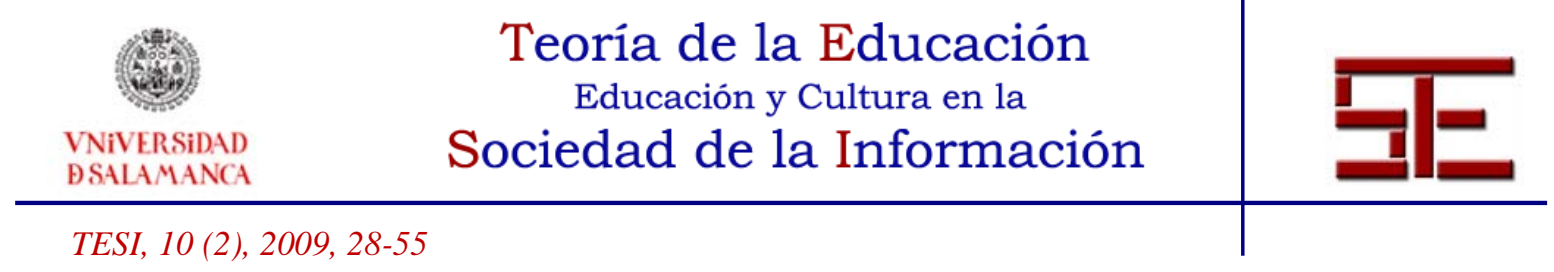

López-Barajas Zayas, E. (2006). Estrategias para la Gestión del Conocimiento. En E. López-Barajas Zayas (coord.), Estrategias de Formación para el Siglo XXI. Barcelona: Ariel.

López-Barajas Zayas, E. (2007). La formación de formadores: un reto para la Ciudadanía. En J. Vergara (coord.), Formación para la Ciudadanía. Barcelona: Ariel.

Marian, J. A. (1993). Teoría de la inteligencia creadora. Barcelona: Anagrama.

Mateos-Aparicio, P. (2001). Dirección y objetivos de la empresa actual. Madrid: Editorial Centro de Estudios Ramón Areces.

Medrano, I. y Suarez, L. (2001). Ensayo sobre estrategias para documentar el conocimiento en una organización. $\mathrm{PH}$ del Instituto Andaluz del Patrimonio Histórico, 9, (36), 234-236.

Nielsen, J. (1990). Hypertext and hypermedia. Boston: Academic Press.

Peretti, J. M. (2000). Todos somos Directores de Recursos Humanos. Barcelona: Edipe.

Polanyi, M. (1975). Meaning. Chicago: The University of Chicago Press.

Poster, M. E. (1980). Estrategia Competitiva. Madrid: CECSA.

Rosenfeld, L. y Morville, P. (1998). Information Architecture for the World Wide Web. Cambridge: O’Reilly.

Rovira, C. (1997). La intranet en instituciones educativas. Net conexión, 17, 64-65.

Rovira, C. (1997). El aula virtual. Net conexión, 18, 65-66.

Rovira, C. (1999). Documents hipertextuals per a entorns virtuals d'aprenentatge. Revista digital d'Humanitats, 1. Extraído de http://www.uoc.es/humfil/digithum.

Rovira, C. (1999). La orientación a objetos en el diseño de hipertextos para la enseñanza-aprendizaje. Cuadernos de documentación Multimedia, 8.

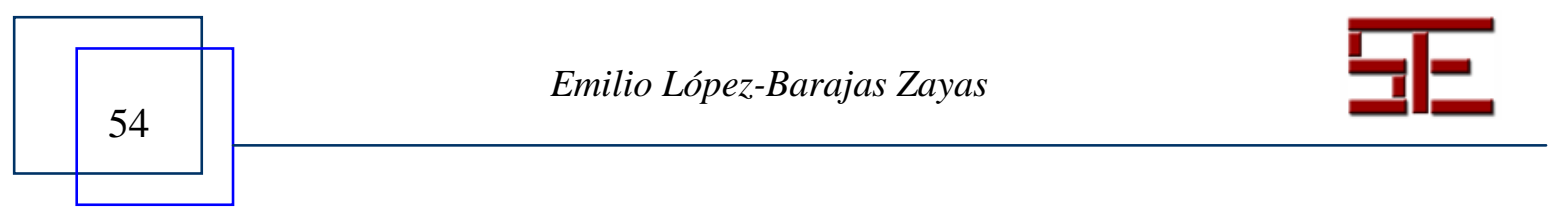




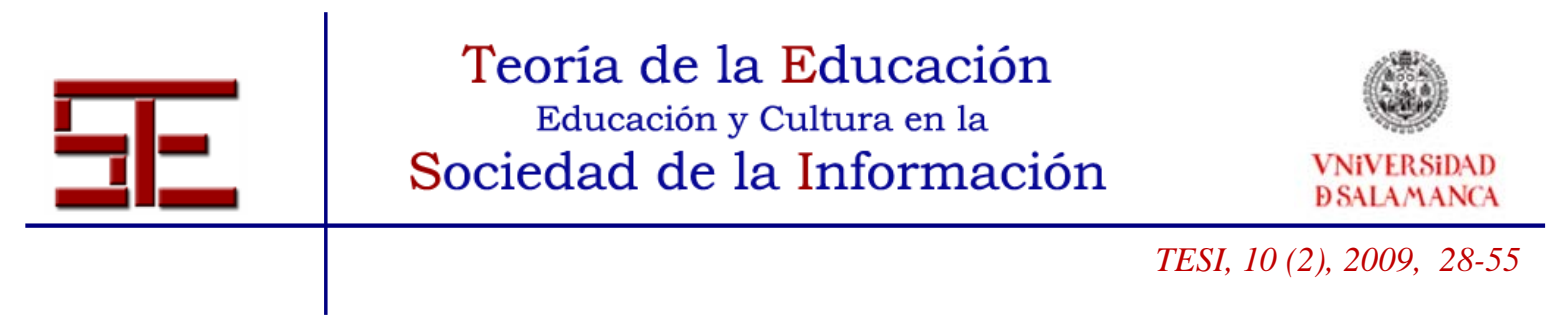

Rumbaugh, J. et al. (1996). Modelado y diseño orientados a objetos. Madrid: Prentice Hall.

Siegel, D. (1997). Técnicas avanzadas para el diseño de páginas Web. Madrid, Anaya: Multimedia.

Socorro. P. (2001). Internet. Madrid: Maeva.

Spiro, R.J. et al. (1994). Cognitive flexibility theory: Advanced knowledge acquisition in ill-structured domains. En R.B. Rudell, M.R.Rudell, H. Singer (eds.), Theoretical models and processes of reading. Newark (DE, US): International Reading Association.

Schein (1998). How hardwired is human behaviour. Harvard Business Review, julioagosto.

The Knowledge Management Resource Center: http://kmworld.com.

Ulrich, D. et. al. (2002): El Futuro de la Dirección de Recursos Humanos. Barcelona: Gestión 2000.com.

Para citar la presente editorial puede utilizar la siguiente referencia:

López-Barajas Zayas, E. (2009). Alfabetización virtual y gestión del conocimiento, en Ortega Sánchez, I. y Ferrás Sexto, C. (Coord.) Alfabetización Tecnológica y desarrollo regional. Revista Electrónica Teoría de la Educación: Educación y Cultura en la Sociedad de la Información. Vol. 10, nº 2. Universidad de Salamanca, pp. 28-55 [Fecha de consulta: $\mathrm{dd} / \mathrm{mm} / \mathrm{aaaa}]$.

http://campus.usal.es/ revistas_trabajo/index.php/revistatesi/article/view/7507/7538

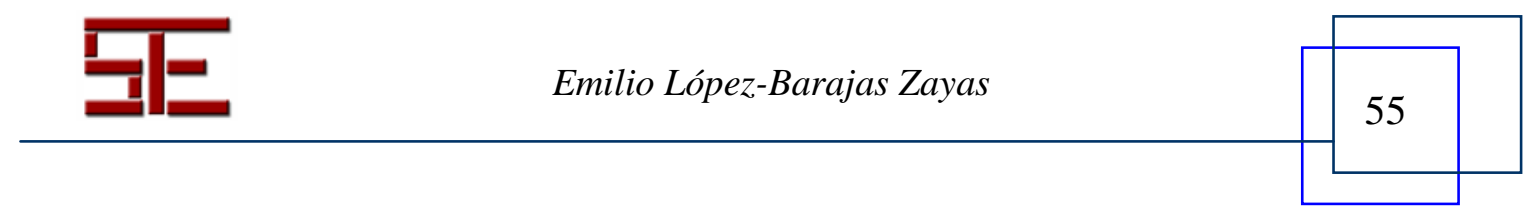

